\title{
AGC-3 Experiment Irradiation Monitoring Data Qualification Final Report
}

\author{
Laurence C. Hull
}

October 2014

The INL is a

U.S. Department of Energy

National Laboratory

operated by

Battelle Energy Alliance

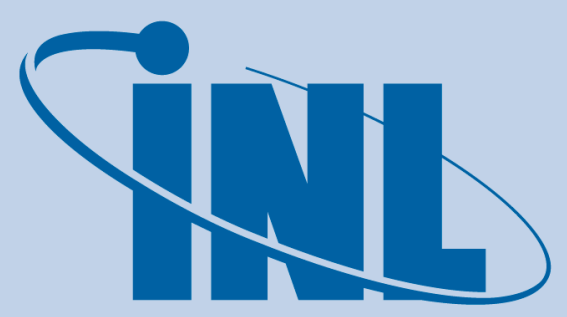

Idaho National Laboratory 


\section{DISCLAIMER}

This information was prepared as an account of work sponsored by an agency of the U.S. Government. Neither the U.S. Government nor any agency thereof, nor any of their employees, makes any warranty, expressed or implied, or assumes any legal liability or responsibility for the accuracy, completeness, or usefulness, of any information, apparatus, product, or process disclosed, or represents that its use would not infringe privately owned rights. References herein to any specific commercial product, process, or service by trade name, trade mark, manufacturer, or otherwise, does not necessarily constitute or imply its endorsement, recommendation, or favoring by the U.S. Government or any agency thereof. The views and opinions of authors expressed herein do not necessarily state or reflect those of the U.S. Government or any agency thereof. 
INL/EXT-14-32425

Revision 1

\title{
AGC-3 Experiment Irradiation Monitoring Data Qualification Final Report
}

\author{
Laurence C. Hull
}

October 2014

\begin{abstract}
Idaho National Laboratory
Very High Temperature Reactor Technology Development Office Idaho Falls, Idaho 83415
\end{abstract}

Prepared for the

U.S. Department of Energy

Office of Nuclear Energy

Under DOE Idaho Operations Office

Contract DE-AC07-05ID14517 

Very High Temperature Reactor Technology Development Office

AGC-3 Experiment Irradiation Monitoring Data Qualification Final Report

INL/EXT-14-32425

Revision 1

October 2014

Approved by:

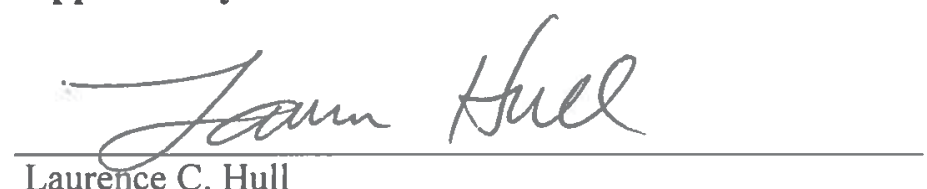

Author

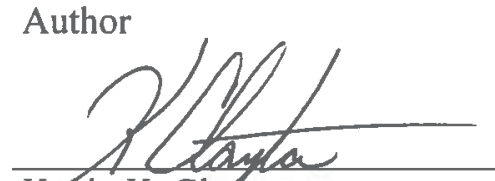

Kevin K. Clayton Independent Technical Reviewer
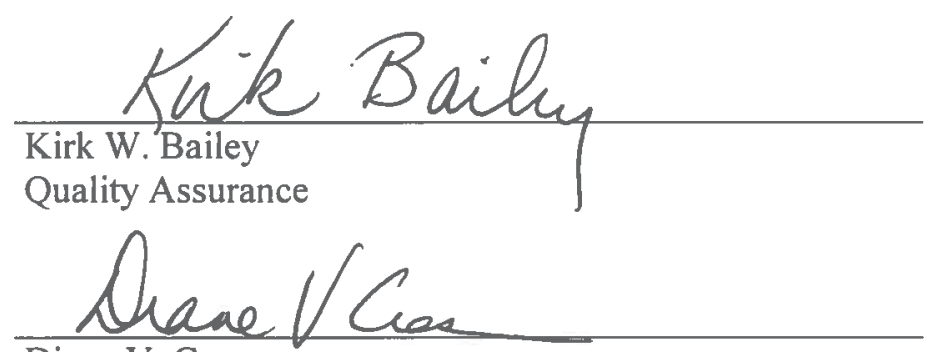

Diane V. Croon

ART Deputy Director
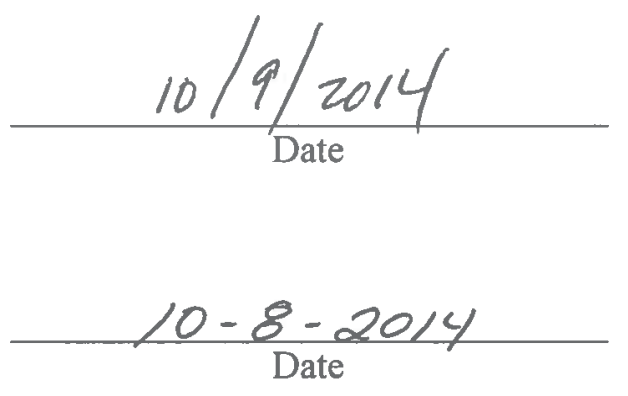

$\frac{10 \cdot 7 \cdot 2014}{\text { Date }}$

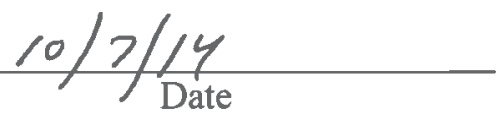





\section{SUMMARY}

The Graphite Technology Development Program will run a series of six experiments to quantify the effects of irradiation on nuclear-grade graphite. The third experiment, Advanced Graphite Creep 3 (AGC-3), began with Advanced Test Reactor (ATR) Cycle 152B on November 27, 2012, and ended with ATR Cycle 155B on April 23, 2014. This report documents qualification of AGC-3 experiment irradiation monitoring data for use by the Very High Temperature Reactor (VHTR) Technology Development Office (TDO) Program for research and development activities required to design and license the first VHTR nuclear plant. Qualified data meet the requirements for data collection and use as described in the experiment planning and quality assurance documents. Failed data do not meet the requirements. Trend data may not meet the requirements, but may still provide some useable information.

All thermocouples (TCs) functioned throughout the AGC-3 experiment. There was one interval between December 18, 2012, and December 20, 2012, where 10 NULL values were reported for various TCs. These NULL values were deleted from the Nuclear Data Management and Analysis System database. All temperature data are Qualified for use by the VHTR TDO Program.

Argon, helium, and total gas flow data were within expected ranges and are Qualified for use by the VHTR TDO Program. Total gas flow was approximately $50 \mathrm{sccm}$ through the AGC-3 experiment capsule. Helium gas flow was briefly increased to $100 \mathrm{sccm}$ during ATR shutdowns.

At the start of the AGC-3 experiment, moisture in the outflow gas line was stuck at a constant value of 335.6174 ppmv for the first cycle (Cycle 152B). When the AGC-3 experiment capsule was reinstalled in ATR for Cycle 154B, a new moisture filter was installed. Moisture data from Cycle 152B are Failed. All moisture data from the final three cycles (Cycles 154B, 155A, and 155B) are Qualified for use by the VHTR TDO Program.

Graphite creep specimens were subjected to one of two loads, 393 or 589 lbf. The experiment plan included three loads, but problems with gas leaks in the rams applying the load to the stacks resulted in lower loads being applied to some of the stacks. While the loads applied were not the loads in the plan, the loads were consistently applied throughout the experiment. Therefore, the reported loads were accurate and can be used in analysis of graphite creep. Loads were consistently within $5 \%$ of the specified values throughout the experiment. Stack displacement increased consistently throughout the experiment with total displacement ranging from 1 to $1.25 \mathrm{in}$. No anomalous values were identified. During ATR outages, a set of pneumatic rams raised the stacks of graphite creep specimens to ensure the specimens were not stuck within the test train. This stack raising was performed three times; all stacks were raised successfully each time. The load and displacement data are Qualified for use by the VHTR TDO Program.

Analyses were conducted on correlations between TCs to look for trends and step changes that might indicate instrument degradation or failure. Correlation analysis was used to identify instances when TCs form short circuits, referred to as virtual junctions, which result in TCs reporting temperatures from some location in the capsule other than the location where they were intended to read. No evidence was found for virtual junctions. Control charts to identify differences between TCs and load cells were not used for the AGC-3 experiment because the experiment lasted only four cycles, and the experiment was removed from ATR between the first and second cycles, and was rotated between the second and third cycles. The assumptions of constant means through the experiment were not likely to be valid under these conditions.

A total of 29,683,751 response values were recorded from irradiation monitoring of the AGC-3 experiment. Data from the three cycles when the experiment capsule were removed from ATR and reported NULL values were deleted from the Nuclear Data Management and Analysis System database. The following data are Failed:

- 30,179 gas moisture values from Cycle 152B between November 27, 2012, and December 18, 2012, that were erroneous due to a stuck moisture filter 
- 29 ram gas pressure values on August 2, 2013, where multiple channels reported a constant negative ram gas pressure of -75.01717 psig.

All other data are Qualified for use by the VHTR TDO Program. 


\section{CONTENTS}

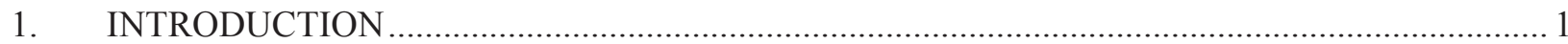

1.1 Graphite Technology Development Program .............................................................. 1

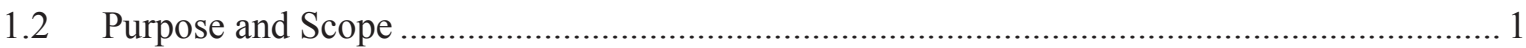

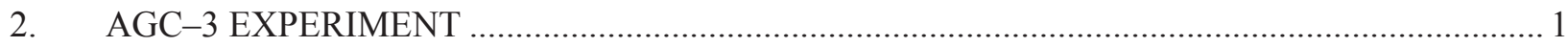

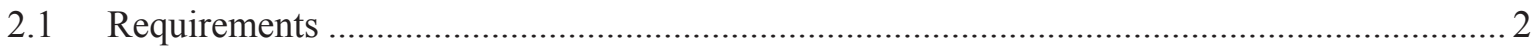

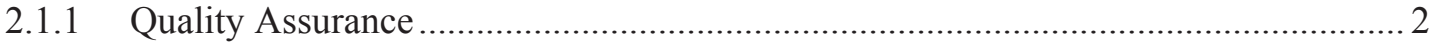

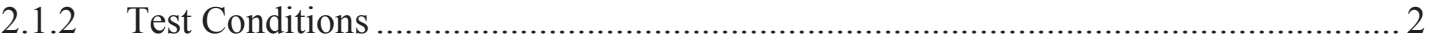

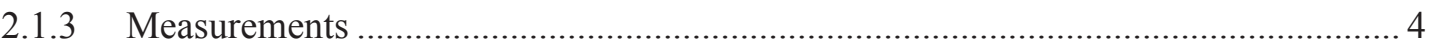

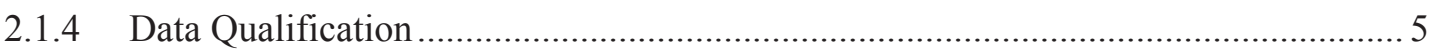

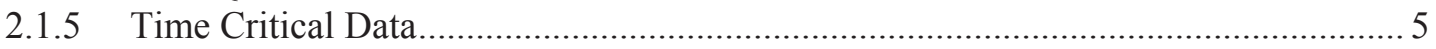

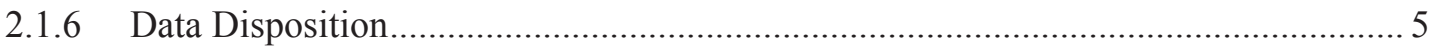

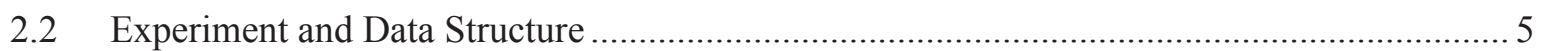

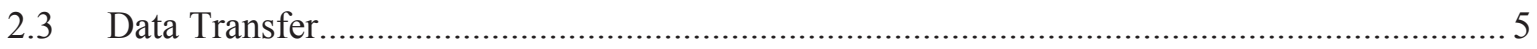

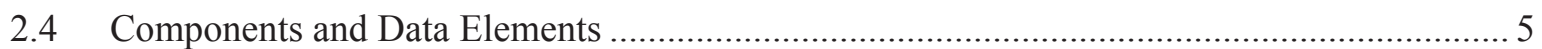

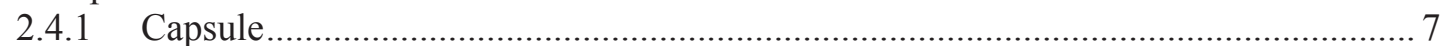

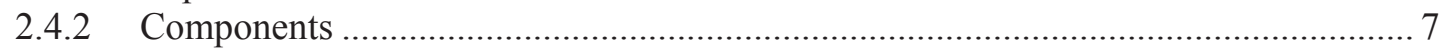

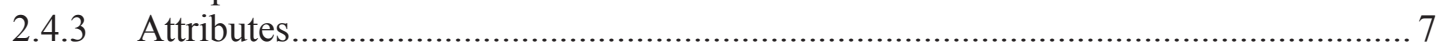

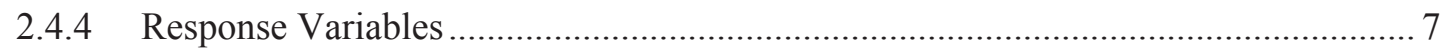

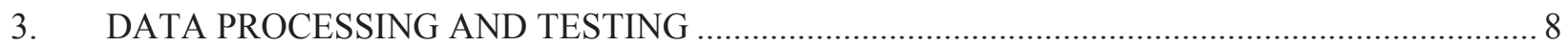

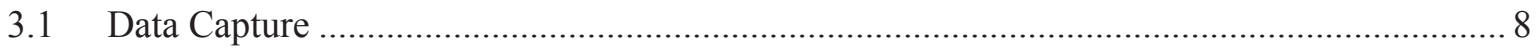

3.2 Advanced Test Reactor Operating Conditions............................................................... 9

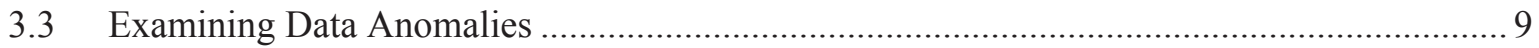

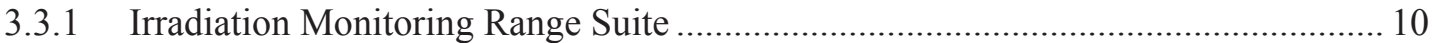

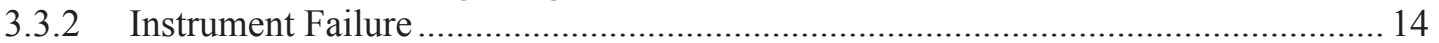

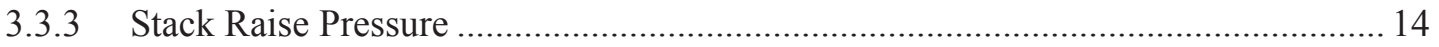

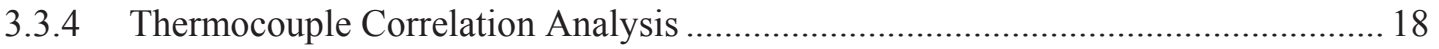

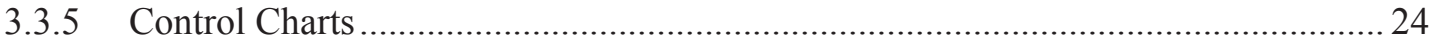

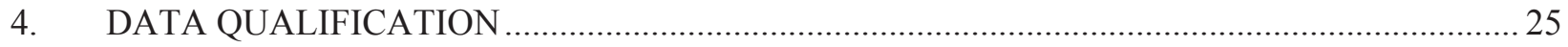

4.1 Conformance to NQA-1-2008/1a-2009, Part I, Quality Assurance Program ........................ 25

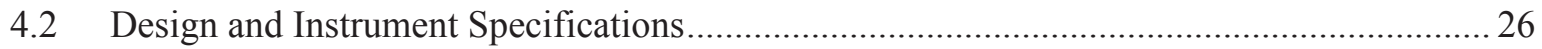

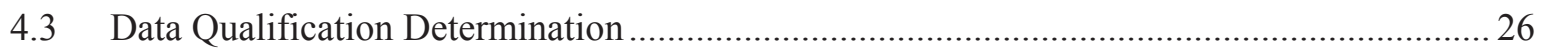

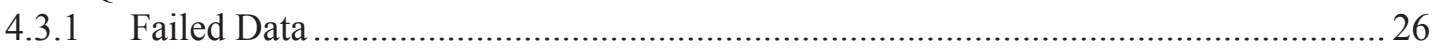

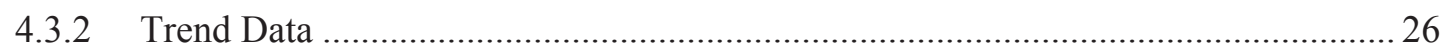

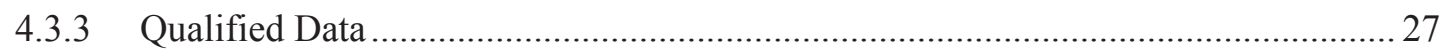

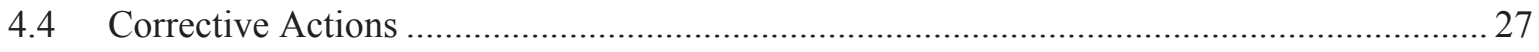

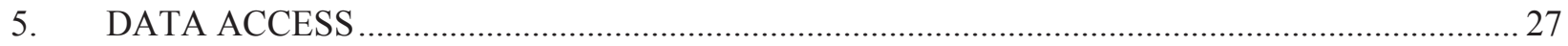

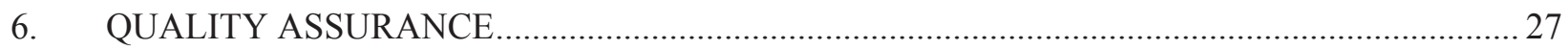

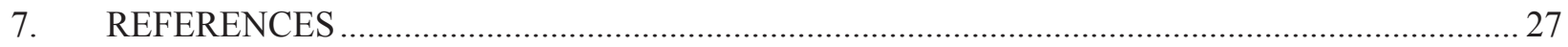

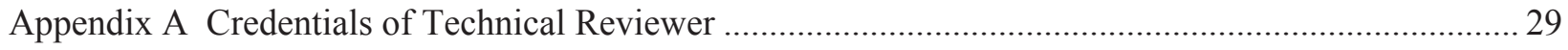




\section{FIGURES}

Figure 1. AGC-3 experiment stack numbers and loads with stack orientation at start of irradiation. Capsule rotated 180 degrees after two irradiation cycles. ......................................................... 3

Figure 2. Stages of data processing in Nuclear Data Management and Analysis System......................... 8

Figure 3. Effective power at east flux trap during AGC-3 experiment...................................................9

Figure 4. Temperature measured by thermocouples distributed in five vertical zones in AGC-3 experiment capsule.

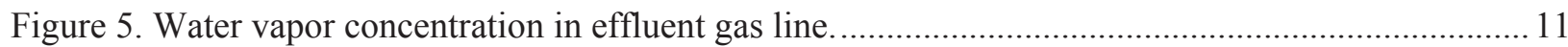

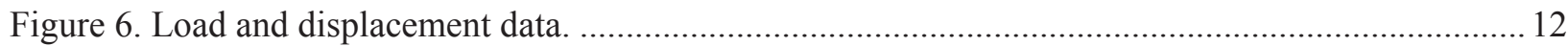

Figure 7. Plots showing argon, helium, and total gas flows through seven zones................................. 13

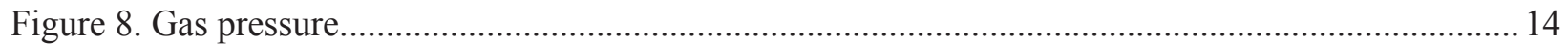

Figure 9. Change in stack position, raise pressure, stack load, and ram gas pressure for stack raising at end of Cycle 152B.

Figure 10. Change in stack position, raise pressure, stack load, and ram gas pressure for stack raising between Cycles 154B and 155A.

Figure 11. Change in stack position, raise pressure, stack load, and ram gas pressure for stack raising at end of AGC-3 experiment after Cycle 155B.

Figure 12. Level of thermocouple with highest correlation to TC01 at Level 8 (978 in.)...................... 18

Figure 13. Level of thermocouple with highest correlation to TC02 at Level 7 (973 in.)...................... 19

Figure 14. Level of thermocouple with highest correlation to TC03 at Level 7 (973 in.)...................... 19

Figure 15. Level of thermocouple with highest correlation to TC04 at Level 6 (966 in.)......................20

Figure 16. Level of thermocouple with highest correlation to TC05 at Level 6 (966 in.).......................20

Figure 17. Level of thermocouple with highest correlation to TC06 at Level 5 (962 in.).......................21

Figure 18. Level of thermocouple with highest correlation to TC07 at Level 4 (954 in.)......................2 1

Figure 19. Level of thermocouple with highest correlation to TC08 at Level 4 (954 in.)......................22

Figure 20. Level of thermocouple with highest correlation to TC09 at Level 3 (948.75 in.)...................22

Figure 21. Level of thermocouple with highest correlation to TC10 at Level 2 (942 in.).......................23

Figure 22. Level of thermocouple with highest correlation to TC11 at Level 2 (942 in.)......................23

Figure 23. Level of thermocouple with highest correlation to TC12 at Level 3 (948.75 in.)..................24

TABLES

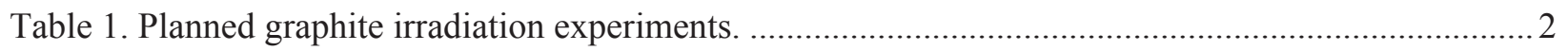

Table 2. Components and response variables monitored for AGC-3 experiment. ................................... 6

Table 3. Tests and test suites defined for evaluating AGC-3 experiment irradiation monitoring

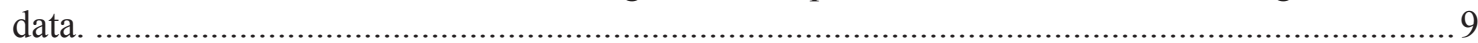

Table 4. Test ranges applied to AGC-3 experiment irradiation monitoring data..................................... 10

Table 5. Number and data state assignment of records with reasons for failure for AGC-3 experiment. 


\section{ACRONYMS}

AGC advanced graphite creep

ATR Advanced Test Reactor

CDCS capsule distributed control system

NDMAS Nuclear Data Management and Analysis System

QA quality assurance

RDAS reactor data acquisition system

TC thermocouple

TDO Technology Development Office

VHTR very high temperature reactor (type) and Very High Temperature Reactor (Program) 


\section{AGC-3 Experiment Irradiation Monitoring Data Qualification Final Report}

\section{INTRODUCTION}

The Very High Temperature Reactor (VHTR) Technology Development Office (TDO) is responsible for research and development activities required to design and license the first VHTR nuclear plant. Materials for use in the VHTR will be tested and characterized to quantify performance in high-temperature and high-fluence environments. This report presents data qualification for the capsule irradiation monitoring data collected from the third advanced graphite creep (AGC) experiment (AGC-3) during Advanced Test Reactor (ATR) Cycles152B, 154B, 155A, and 155B. The AGC-3 experiment capsule was removed from ATR during Cycles 153A, 153B, and 154A. Irradiation occurred from November 27, 2012, to April 23, 2014.

\subsection{Graphite Technology Development Program}

The Graphite Technology Development Program provides data to support the design of graphite core components within the specific reactor service conditions of the VHTR (PLN-2497 ${ }^{1}$ ). The Graphite Technology Development Program will run a series of six experiments to quantify the effects of irradiation on nuclear-grade graphite. The objectives of the graphite irradiation experiments are to demonstrate that commercially-available nuclear-grade graphite exhibits acceptable nonirradiated and irradiated properties for use in nuclear reactor structural components and establish the lifetime under VHTR neutron radiation and temperature regimes for specific graphite types.

To meet these objectives, the Graphite Technology Development Program has established the following data collection tasks:

- Measure the thermophysical properties of graphite specimens before and after irradiation in ATR

- Measure the radiation induced creep at high temperature and high radiation dose.

Data collected during specimen irradiation will be used to quantify the temperatures, radiation doses, and compressive stresses experienced by specimens. The data are necessary to develop an understanding of the behavior of graphite in radiation fields.

\subsection{Purpose and Scope}

The report documents qualification of AGC-3 experiment irradiation monitoring data following MCP-2691. ${ }^{2}$ This report also documents whether AGC-3 experiment irradiation monitoring data meet the requirements for data collection as specified in technical and functional requirements documents and quality assurance (QA) plans. Data handling is described showing how data are passed from the data collection experiment to the Nuclear Data Management and Analysis System (NDMAS) team. The data structure is described, including data batches, components, attributes, and response variables. The description of the approach to data qualification includes the steps taken to qualify the data and the specific tests used to verify that the data meet requirements. Finally, the current status of the data received by NDMAS from the AGC-3 experiment is presented with summarized information on test results and resolutions. This report addresses all of the irradiation monitoring data collected during the AGC-3 experiment.

\section{AGC-3 EXPERIMENT}

The AGC irradiation test series supports the acquisition of irradiated graphite performance data to assist in selecting the technology used for the VHTR. Six irradiation experiments are planned to investigate compressive creep in graphite subjected to a neutron field, and to obtain irradiated mechanical 
properties of vibrationally-molded, extruded, and isomolded graphite for comparison as identified in PLN-2494 3 and shown in Table 1. The major objective of the AGC-3 experiment was to provide irradiation creep data. This required irradiation of matched pairs of stressed and unstressed specimens, which was achieved using the axial flux symmetry in ATR, with a stressed specimen above the symmetry plane matched to an unstressed specimen placed below the symmetry plane. This arrangement was used in six channels around the periphery of a graphite experiment capsule with a center channel used for additional unstressed specimens.

Table 1. Planned graphite irradiation experiments.

\begin{tabular}{|c|c|}
\hline Experiment & Experiment Description \\
\hline AGC-1 & $600^{\circ} \mathrm{C}$ and 3 to $6 \mathrm{dpa}$ \\
\hline AGC-2 & $600^{\circ} \mathrm{C}$ and 0.5 to $3 \mathrm{dpa}$ \\
\hline AGC-3 & $900^{\circ} \mathrm{C}$ and 0.5 to $3 \mathrm{dpa}$ \\
\hline AGC-4 & $900^{\circ} \mathrm{C}$ and 3 to $6 \mathrm{dpa}$ \\
\hline AGC-5 & $1200^{\circ} \mathrm{C}$ and 0.5 to $3 \mathrm{dpa}$ \\
\hline AGC-6 & $1200^{\circ} \mathrm{C}$ and 3 to $6 \mathrm{dpa}$ \\
\hline dpa $=$ displacements per atom. \\
\hline
\end{tabular}

The AGC-3 experiment followed the design of the AGC-1 and AGC-2 experiments very closely. The AGC-3 experiment was irradiated in the east flux trap of ATR to a peak irradiation dose of about 3 dpa at an intended irradiation temperature of about $900^{\circ} \mathrm{C}$. The irradiation had a planned duration of 260 effective-full-power days (ECAR-1788 ${ }^{4}$ ) with an actual irradiation of 209.5 effective-full-power days. The AGC-3 experiment capsule was removed from ATR during Cycles 153A, 153B, and 154A. At the beginning of the AGC-3 experiment, Stack 1 was oriented east, facing the core center. Between Cycles 154B and 155A, the AGC-3 experiment capsule was rotated 180 degrees to more evenly distribute radiation dose.

\subsection{Requirements}

Technical and functional requirements for AGC-3 experiment capsule irradiation monitoring are presented in TFR-791, ${ }^{5}$ TFR-509, ${ }^{6}$ and TFR-510. ${ }^{7}$ The AGC-3 experiment used the same temperature control and compressive load systems as the AGC-1 and AGC-2 experiments and the same technical and functional requirements.

\subsubsection{Quality Assurance}

The AGC-3 experiment was conducted within an NQA-1-2008/1a-2009, Part I, ${ }^{8,9}$ compliant QA program as implemented in PLN-2690. ${ }^{10}$

\subsubsection{Test Conditions}

\subsubsection{Temperature}

The planned AGC-3 experiment maximized the number of specimens at a temperature of $900 \pm 50^{\circ} \mathrm{C}$ along the 1.22-m length of the ATR core. Since the flux decreases rapidly at the ends of the experiment capsule, tungsten gamma heating rods were installed at each end of the graphite specimen stacks to increase heating at the end of the stacks. The time-average maximum temperature for each creep specimen was not to be $>950^{\circ} \mathrm{C}$, nor was each creep specimen's time-average minimum temperature to be $<850^{\circ} \mathrm{C}(\mathrm{TFR}-791)$. 


\subsubsection{Load}

A mechanical load is applied to the outer six perimeter stacks to induce accelerated irradiation creep within the graphite test specimens during irradiation. To evenly balance the applied stresses on the graphite body within the AGC-3 experiment capsule, each pair of opposing stacks were planned to be stressed to one of three stress levels: $13.8 \mathrm{MPa}$ (393 lbf, 2,000 psi), $17.3 \mathrm{MPa}$ (491 lbf, $2500 \mathrm{psi}$ ), or 20.7 $\mathrm{MPa}$ (589 lbf, $3000 \mathrm{psi}$ ) (Figure 1). An imposed mechanical stress was not planned for the center stack. Six pneumatic rams located in the 5-in. pressure boundary generated the load. Graphite pushrods transmitted the force of the ram's piston onto the graphite columns. The loading system had the capability to compensate for thermal expansion and expected graphite shrinkage during the experiment. This was accomplished by using administrative feedback from in-line load cells (determining pressure response) between the pneumatic rams and pushrods to maintain the correct loading on the columns via the correct pressure in the cylinders.

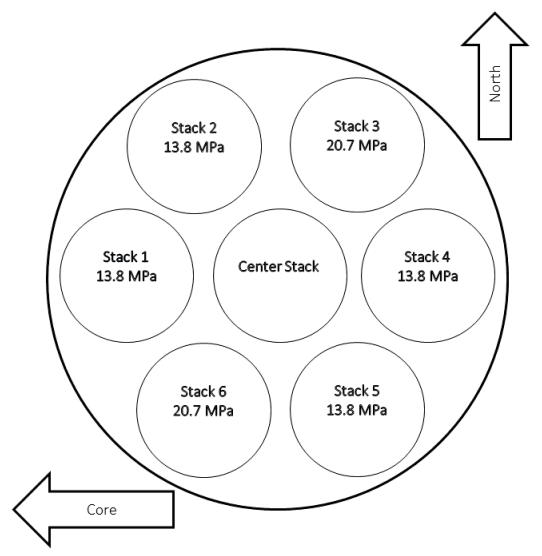

Figure 1. AGC-3 experiment stack numbers and loads with stack orientation at start of irradiation. Capsule rotated 180 degrees after two irradiation cycles.

The AGC-3 experiment encountered a high gas leak rate $(5.6 \mathrm{~L} / \mathrm{min}$ system leak rate versus the average rate of $1.0 \mathrm{~L} / \mathrm{min}$ for the $\mathrm{AGC}-1$ and $\mathrm{AGC}-2$ experiments) in the compressive load control system, with the significant increase attributed primarily to the portion of the system providing the load on Stack 4. Therefore, a compressive load was not placed on Stack 4 until the source and future consequences of the leak were evaluated. In addition, a compressive load was not placed on Stack 1 (diametrically opposite and load pair companion to Stack 4 [Figure 1]) to prevent eccentrically loading the graphite specimen holder, which could possibly result in damaging the holder. The compressive loads on Stacks 2 and 5 were reduced from 17.3 to 13.8 MPa on December 5, 2012, to maximize the range of stack loading from the experiment if Stacks 1 and 4 were not able to have compressive loads.

Since the compressive loads have to remain constant throughout the irradiation, there were two major concerns: (1) the leak rate may increase to the point that the load could not be maintained; and (2) sufficient helium may not be obtainable to overcome the leak rate due to a national shortage of helium. Data from the inlet and outlet system flow meters indicated that the source of the leak was internal to the test train, most probably within the pneumatic ram for Stack 4. After discussions with the vendor and reviewing data taken during preassembly testing of the pneumatic rams, it was decided to test the system to determine the stability of the leak rate. The desired loads were imposed on Stacks 1 and 4 on Tuesday, December 11, 2012, and the leak rate was monitored until Monday, December 17, 2012. The leak rate was extremely stable with essentially no perceptible change over the six-day period. This result indicated that the leak was most likely located in a metallic component (such as a fitting) and should remain very stable throughout the irradiation. Sufficient helium was located to support maintaining the load on the stacks for the duration of Cycle 152B. The compression gas was switched from helium to 
argon at the end of Cycle 152B. With the gas shortage issue resolved, and the determination that the leak rate was stable, it was concluded that loads could successfully be applied to Stacks 1 and 4 for the duration of the AGC-3 experiment.

A compressive load of $13.8 \mathrm{MPa}$ was applied to Stacks 1 and 4 for the duration of the experiment. Stacks 2 and 5 remained at $13.8 \mathrm{MPa}$ for the duration of the experiment so that the load applied to these stacks would be constant. Therefore, four stacks were loaded to $13.8 \mathrm{MPa}$ for the experiment with two stacks loaded to $20.7 \mathrm{MPa}$ (Figure 1).

\subsubsection{Fluence}

Specimens were exposed to fast neutron fluence $(\mathrm{E}>0.1 \mathrm{MeV})$ between $0.5 \mathrm{E}+21 \mathrm{n} / \mathrm{cm}^{2}$ and $5.5 \mathrm{E}+21 \mathrm{n} / \mathrm{cm}^{2}$. The fluence difference between graphite specimens at equal distances above and below the ATR core centerline was not to exceed $10 \%$. Fluence, determined by computer modeling of reactor physics, was verified by flux wires installed in the AGC-3 experiment capsule.

\subsubsection{Measurements}

\subsubsection{Temperature}

Thermocouples (TCs) recorded AGC-3 experiment capsule temperatures and were selected based on operating range and the ability to withstand the effects of the high neutron fluences planned for the irradiation. Temperature was measured at 12 locations throughout the vertical extent of the capsule.

\subsubsection{Temperature Control Gas}

All temperature-control gases entering the AGC-3 experiment capsule were filtered to remove oxygen and moisture. The gas was designed to contain $<5$ ppmv $\mathrm{O}_{2}$ and $<10$ ppmv moisture prior to entering the experiment. The gas was a mixture of helium and argon with the ratio adjusted based on feedback from TCs located in the test train. Gas flow rates, line pressures, and outlet moisture were recorded at 1-minute intervals.

To create an even temperature distribution along the length of the capsule, the capsule was divided into five zones vertically. A TC in each zone provided feedback to the associated gas controller to adjust the argon/helium gas ratio in that zone to control temperature at the desired level. Two additional gas channels provided gas to the capsule, one inside the graphite holder and one outside the heat shield.

\subsubsection{Load}

The pneumatic rams applied stress to the six stacks of graphite specimens and were controlled by applying the desired load within $\pm 5 \%$. The load cells have a maximum load rating of $\pm 1,000 \mathrm{lbf}$ with no more than a $\pm 5 \%$ error in load measurement. During ATR outages, the compressive load from the upper pneumatic rams was removed and lower pneumatic rams raised the specimen stacks to ensure that the graphite stack was not lodged or jammed in the graphite holder. Experiment data were recorded at 1-minute intervals.

\subsubsection{Advanced Test Reactor Operating Conditions}

ATR data that described the core neutronics and thermal-hydraulics environment were gathered. These data will assist the physics analysis necessary for the final test report. Data provided include individual lobe powers and shim cylinder positions. These data were recorded and backed up on a separate storage device once every minute.

\subsubsection{Neutron Dosimetry}

The volume average fast neutron fluence for the graphite specimens was inferred from physics calculations normalized by the flux wire measurements performed after AGC-3 experiment capsule disassembly. The flux wires were chosen to measure the fast spectrum $>0.1 \mathrm{MeV}$. 


\subsubsection{Data Qualification}

All electronically-recorded data were evaluated for validation and qualified against data collection requirements. The following parameters were Qualified for use by the VHTR TDO Program, and are therefore identified as Type $A^{\text {a }}$ data: TC temperatures, pneumatic ram pressures, load cell output, stack position, constituent temperature-control-gas flow rates and pressure, and outlet moisture.

\subsubsection{Time Critical Data}

Technical staff had access to the AGC-3 experiment capsule monitoring data to evaluate whether experimental parameters were within specifications, determine whether instruments functioned as planned, and assess the experiment's progress. TC temperatures, pneumatic ram gas pressures, load cell output, stack position, constituent temperature-control-gas flow rates and pressure, and gas moisture were displayed on the Web and made accessible during the experiment.

\subsubsection{Data Disposition}

Irradiation monitoring data consisting of TC temperatures, pneumatic ram pressures, load cell output, stack position, constituent temperature-control-gas flow rates and pressure, and measured gas moisture

were archived in NDMAS. Form $435.77,{ }^{11}$ covering the irradiation monitoring data, was filed with VHTR Records Management in accordance with PLN-3319. ${ }^{12}$

\subsection{Experiment and Data Structure}

The design of the Graphite Experimental Program data storage structure is based on a hierarchy of 1) experiment, 2) data stream, 3) data batch, and 4) data element. This section expands on the hierarchy by explaining the four levels and the types of information collected for them. Six experiments have been planned in the Graphite Technology Development Program (Table 1). The AGC-3 experiment consists of four data streams: preirradiation characterization, irradiation monitoring, postirradiation examination, and thermal and neutronics calculations. This report addresses qualification of the irradiation monitoring data stream of the AGC-3 experiment.

\subsection{Data Transfer}

Two data acquisition systems at ATR collected AGC-3 experiment irradiation monitoring data. The reactor data acquisition system (RDAS) collected ATR power and control data and the capsule distributed control system (CDCS) collected capsule monitoring data. CDCS data files were placed on the \} \backslash \mathrm { FDAS } server every hour and RDAS data files were placed on the IIFDAS server every 2 hours. Both types of files were placed on the server 55 minutes after the hour. A batch file invoked by Windows Task Scheduler triggering every hour on the hour executed the download. The batch process created two folders, "Data" and "Log," for storing the incoming files and the activity log and copies the incoming files into these folders. These folders were moved and zipped into an archive folder once the download was complete.

\subsection{Components and Data Elements}

The data element is the recorded single variable value that provides information about the system or object being measured. Data elements are divided into response and attribute elements. Simply defined, response elements are numeric values that describe the response of the object or system such as pressure, temperature, and elastic modulus. Attribute elements generally describe the object or system being measured, or provide category or spatial information about the object such as graphite grade or irradiation position.

a. Type A data are data collected within an NQA-1-2008/1a-2009, Part I, QA program that are collected to meet specific requirements with regard to fuel licensing with independent verification that those requirements were met. 
Both response and attribute values are associated with a component - the generic name for the object or system being measured. Examples of components are a capsule, an outer gas annulus, or a TC.

Component attributes provide additional information about the components. The components established for the AGC-3 experiment irradiation monitoring data stream are listed in Table 2. Multiple response variables can be associated with a single component.

Table 2. Components and response variables monitored for AGC-3 experiment.

\begin{tabular}{|c|c|c|c|}
\hline \multirow{2}{*}{\multicolumn{2}{|c|}{ Component }} & & \\
\hline & & Component Attribute & Response Variables \\
\hline \multicolumn{2}{|c|}{ Capsule } & & Raise pressure (psig) \\
\hline \multirow[t]{12}{*}{ TCs } & $\mathrm{TC} 01$ & $45.7 \mathrm{~cm}$ above ATR core centerline & \multirow[t]{12}{*}{ Temperature $\left({ }^{\circ} \mathrm{C}\right)$} \\
\hline & $\mathrm{TC} 02$ & $33.0 \mathrm{~cm}$ above ATR core centerline & \\
\hline & $\mathrm{TC} 03$ & $33.0 \mathrm{~cm}$ above ATR core centerline & \\
\hline & TC04 & $15.2 \mathrm{~cm}$ above ATR core centerline & \\
\hline & TC05 & $15.2 \mathrm{~cm}$ above ATR core centerline & \\
\hline & TC06 & $5.1 \mathrm{~cm}$ above ATR core centerline & \\
\hline & TC07 & $15.2 \mathrm{~cm}$ below ATR core centerline & \\
\hline & TC08 & $15.2 \mathrm{~cm}$ below ATR core centerline & \\
\hline & TC09 & $28.6 \mathrm{~cm}$ below ATR core centerline & \\
\hline & TC10 & $45.7 \mathrm{~cm}$ below ATR core centerline & \\
\hline & TC11 & $45.7 \mathrm{~cm}$ below ATR core centerline & \\
\hline & TC12 & $28.6 \mathrm{~cm}$ below ATR core centerline & \\
\hline \multirow[t]{7}{*}{ Channels } & 1 & & \multirow{6}{*}{$\begin{array}{ll}\text { - } & \text { Ram gas pressure (psig) } \\
\text { - } & \text { Load (lbf) } \\
\text { - } & \text { Specimen position (in.) }\end{array}$} \\
\hline & 2 & & \\
\hline & 3 & & \\
\hline & 4 & & \\
\hline & 5 & & \\
\hline & 6 & & \\
\hline & Center & & \\
\hline \multirow[t]{5}{*}{ Gas zones } & 1 & 61 to $41 \mathrm{~cm}$ below ATR core centerline & \multirow{5}{*}{$\begin{array}{ll}\text { - } & \text { Helium gas flow }(\mathrm{sccm}) \\
\text { - } & \text { Argon gas flow }(\mathrm{sccm}) \\
\text { - } & \text { Total gas flow }(\mathrm{sccm}) \\
\text { - } & \text { Gas pressure (psia) }\end{array}$} \\
\hline & 2 & 41 to $20 \mathrm{~cm}$ below ATR core centerline & \\
\hline & 3 & $20 \mathrm{~cm}$ below to $20 \mathrm{~cm}$ above ATR core centerline & \\
\hline & 4 & 20 to $41 \mathrm{~cm}$ above ATR core centerline & \\
\hline & 5 & 41 to $61 \mathrm{~cm}$ above ATR core centerline & \\
\hline \multicolumn{2}{|c|}{$\begin{array}{l}\text { Gas annulus inside } \\
\text { heat shield (Zone 6) }\end{array}$} & & $\begin{array}{ll}\text { - } & \text { Helium gas flow }(\mathrm{sccm}) \\
\text { - } & \text { Argon gas flow }(\mathrm{sccm}) \\
\text { - } & \text { Gas pressure (psia) } \\
\end{array}$ \\
\hline \multicolumn{2}{|c|}{$\begin{array}{l}\text { Gas annulus outside } \\
\text { heat shield (Zone 7) }\end{array}$} & & $\begin{array}{ll}\text { - } & \text { Helium gas flow }(\mathrm{sccm}) \\
\text { - } & \text { Trgon gas flow }(\mathrm{sccm}) \\
\text { - } & \text { Gas pressure (psia) } \\
\end{array}$ \\
\hline \multicolumn{2}{|c|}{ Outlet gas line } & & $\begin{array}{ll}\text { - } & \text { Moisture content (ppmv) } \\
\text { - } & \text { Gas pressure (psia) } \\
\end{array}$ \\
\hline
\end{tabular}




\subsubsection{Capsule}

The AGC-3 experiment capsule is approximately $1.22 \mathrm{~m}$ long and contains seven channels that were filled with stacks of graphite specimens. A stress was applied to the stressed creep specimens in the upper housing of the six peripheral channels which were paired with unstressed graphite specimens in the lower housing (TFR-791). The apparent irradiation creep strain was determined from the difference in the dimensional changes between stressed and unstressed specimens irradiated at the same temperature and to the same neutron damage dose. In addition to the unstressed creep control specimens, each specimen stack also contained a number of smaller piggyback specimens of other VHTR-relevant graphite. The central channel contained unstressed piggyback specimens, a few specimens of highly-oriented pyrolytic graphite, and a few experimental graphite specimens with $\mathrm{SiC}$ coatings.

\subsubsection{Components}

The highest level component in the component-assembly tree is the capsule. For AGC experiments, there is only one capsule. Components are selected to represent the physical system collecting the data. The components consist of one capsule, 12 TCs, seven channels, five gas zones, a gas annulus inside the heat shield, a gas annulus outside the heat shield, and an outlet gas line (Table 2).

\subsubsection{Attributes}

TCs and gas zones have attributes that identify the relevant location in the AGC capsule. For TCs, the position of the TC in the capsule is given in terms of distance from the core centerline. For gas zones, the location is described by the vertical elevation range over which the zone extends (for zones 1 to 5) or the position of the zone relative to the heat shield (Table 2).

\subsubsection{Response Variables}

Response variables, the parameters monitored on capsule systems, are also specified in Table 2. Pneumatic rams provided the compressive load on the stressed specimens in the six specimen stacks (TFR-510). The upper rams and lower bellows were located away from the high neutron and gamma fields of the ATR core. Stainless-steel pushrods in the leadout to graphite pushrods inside the high-temperature graphite holder transmitted the force exerted on the specimens. An in-line load cell, located above the ATR core and between the pneumatic rams and the push bars, monitored the force on the graphite specimens in each stack. The pushrod position was monitored to record the compression of the graphite specimens.

Twelve TCs were distributed between the specimen stacks and arranged throughout the height of the capsule to monitor temperature during irradiation. The TCs were installed as deemed appropriate to monitor and control the specimen temperatures during irradiation.

The temperature inside the capsule was controlled by altering the thermal conductivity of gas in the five gas zones and the annulus around the capsule. The gas flow control system used temperature readings from selected TCs to control the experiment temperature in each zone by adjusting the argon-to-helium gas ratio in the five vertical zones along the annulus of the experiment capsule (TFR-509). The helium and argon gas flow rates, total gas flow, and gas pressure were monitored.

The fast neutron fluence $(\mathrm{E}>0.1 \mathrm{MeV})$ was calculated across the axial length of the capsule from detailed physics algorithms. The calculated fluence values are to be confirmed through post irradiation examination (PIE) measurements of flux wires located within the six peripheral channels. The composition of the gas stream will be used in heat transport simulations to calculate the average temperature at the specimen locations. 


\section{DATA PROCESSING AND TESTING}

Data generated by the AGC-3 experiment must be qualified for use, stored in a readily-accessible electronic form, and controlled to ensure the correct data are used. The graphite data were stored in NDMAS to address these requirements. NDMAS provides a controlled and secure electronic data storage environment, supports data qualification, identifies the qualification status of data, provides data analysis and modeling products, and makes data available for use to the Graphite Technology Development Program (PLN-2709 ${ }^{13}$ ). The data delivery portal is Web-based so program members can access the system and review the data; obtain analysis results, including statistics and graphics; create slide presentations; and download data for advanced analysis. By performing these roles, NDMAS assures the program uses the correct data and data of known quality are available to support future licensing of a VHTR.

Data received from the AGC-3 experiment were archived on the NDMAS server as shown in Figure 2. The native files were then read and the data captured to the NDMAS Microsoft Structured Query Language ${ }^{\circledR} 2008$ database (also known as "the vault"). A complete description of NDMAS and the NDMAS processes is contained in INL/EXT-12-27594 ${ }^{14}$ and INL/EXT-09-16327. ${ }^{15}$

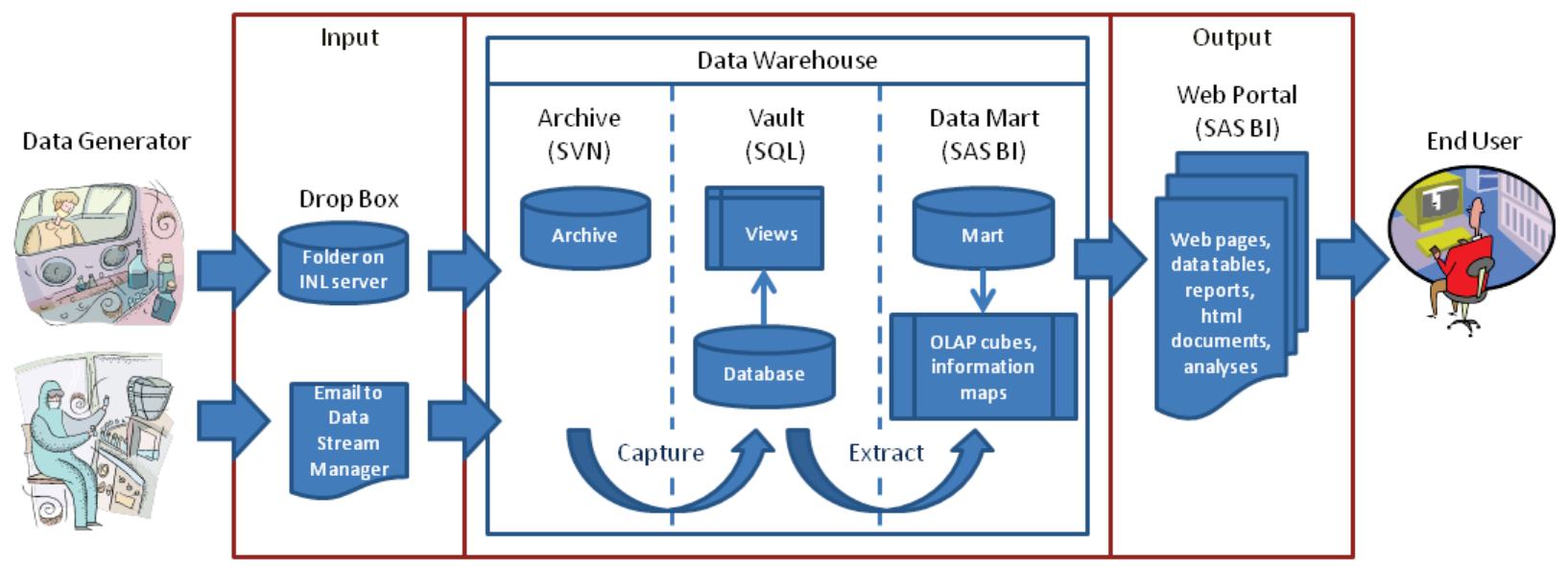

Figure 2. Stages of data processing in Nuclear Data Management and Analysis System.

\subsection{Data Capture}

Two custom applications were developed in C\# to capture data. These applications are installed on $\mathrm{C}:$ |program files $\backslash \mathrm{INL} \backslash \mathrm{NDMASImporter} \backslash$ as the application root folder on the \ISASAP server. One of the two applications is a service base application that ensures the second application is running and available to process data files to the database. This service base application is called NDMASService.exe and is registered as a system service and launched automatically when the system boots up. The second application is called NDMASImporter.exe, which watches a specified set of folders for new data files.

Data capture is performed using computer codes that are tested, reviewed, and maintained in a controlled program repository. The codes are tested by manually comparing data pulled from the NDMAS database to the original data in the native RDAS and CDCS files. Once the capture codes have been verified by manual inspection, subsequent data capture events are verified using an automated comparison between data pulled from the vault and data pushed into the vault. When changes are made to the capture codes, the manual verification is performed again. The verified code is stored under configuration control to assure the same verified project is used to capture subsequent files. Once the capture of the data is verified, the Data_State_EID is changed from raw to capture passed. 


\subsection{Advanced Test Reactor Operating Conditions}

ATR operating conditions data were collected under an NQA-1-2008/1a-2009, Part I, QA program maintained by ATR Operations, and are not Qualified for use by the VHTR TDO Program. Effective power at the east flux trap was calculated as the average of the lobe powers at the southeast, northeast, and center lobe. Effective power averaged 19.1 MW during capsule irradiation as shown in Figure 3. The AGC-3 experiment capsule was removed from ATR during Cycles 153A, 153B, and 154A.

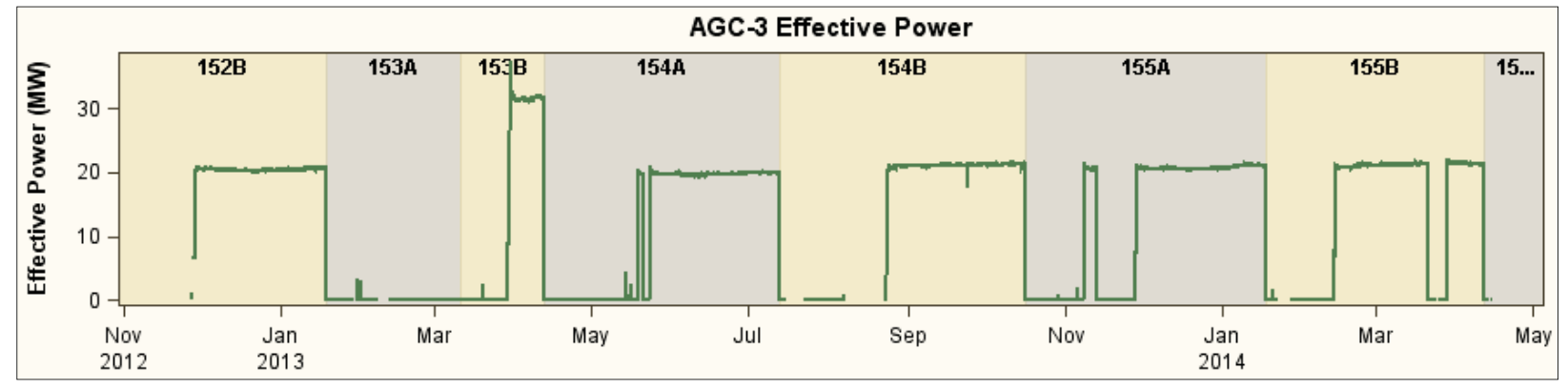

Figure 3. Effective power at east flux trap during AGC-3 experiment.

\subsection{Examining Data Anomalies}

Once the irradiation monitoring data were captured in the NDMAS database, a number of tests were ran to examine the data for anomalies. Anomalies are data with values outside the range of expected behaviors. Some anomalies may be errors or transient events that produced real data outside of normal ranges. The anomalies are reviewed as part of the data qualification process. This section discusses the tests and basis for the tests and presents the test results. Qualification decisions based on the test results are presented in Section 4.

Tests developed to verify data are listed in Table 3 . The tests are grouped into test suites. Most tracking of data testing in NDMAS is done at the test suite and data batch level. However, errors and error resolutions are tracked at the data element level.

Table 3. Tests and test suites defined for evaluating AGC-3 experiment irradiation monitoring data.

\begin{tabular}{|c|c|c|c|}
\hline Test Type & Test Name & Test Description & Applied To \\
\hline \multirow[t]{2}{*}{ Accuracy } & $\begin{array}{l}\text { Irradiation } \\
\text { monitoring } \\
\text { range }\end{array}$ & $\begin{array}{l}\text { Compares response values to anticipated } \\
\text { acceptable ranges from the experiment. } \\
\text { Identifies anomalous values that fall outside } \\
\text { the expected range. }\end{array}$ & $\begin{array}{l}\text { Temperature, gas flow, gas } \\
\text { pressure, humidity, upper ram } \\
\text { gas pressure, compressive } \\
\text { load, and specimen position }\end{array}$ \\
\hline & $\begin{array}{l}\text { Instrument } \\
\text { failure }\end{array}$ & $\begin{array}{l}\text { Fails data collected from an instrument } \\
\text { deemed to no longer provide reliable data. }\end{array}$ & $\begin{array}{l}\text { All response variables as } \\
\text { needed }\end{array}$ \\
\hline \multirow[t]{3}{*}{ Analysis } & $\begin{array}{l}\text { TC spatial } \\
\text { correlation }\end{array}$ & $\begin{array}{l}\text { Calculates correlations between daily average } \\
\text { temperatures. TCs adjacent to each other } \\
\text { should be more highly correlated than TCs at } \\
\text { different elevations. }\end{array}$ & TC01 through TC12 \\
\hline & $\begin{array}{l}\text { TC difference } \\
\text { control charts }\end{array}$ & $\begin{array}{l}\text { Charts the temperature difference between } \\
\text { TCs, which should be similar over time. } \\
\text { Trends and discontinuities in the data suggest } \\
\text { that one of the TCs is drifting or failing. }\end{array}$ & TC01 through TC12 \\
\hline & $\begin{array}{l}\text { Load cell } \\
\text { difference } \\
\text { control charts }\end{array}$ & $\begin{array}{l}\text { Charts the load difference between channels, } \\
\text { which should be similar over time. Trends and } \\
\text { discontinuities suggest that a load cell is } \\
\text { drifting or failing. }\end{array}$ & $\begin{array}{l}\text { Load cells for Channels } 1 \\
\text { through } 6\end{array}$ \\
\hline
\end{tabular}




\subsubsection{Irradiation Monitoring Range Suite}

The range tests evaluate whether instrument readings fall within an expected range of values. The expected ranges for instruments are listed in Table 4. Range tests do not test for conformance to specifications so the range values listed do not match specifications for test parameters.

Table 4. Test ranges applied to AGC-3 experiment irradiation monitoring data.

\begin{tabular}{|l|c|l|}
\hline Response Variable & Expected Range & \multicolumn{1}{|c|}{ Comments } \\
\hline Temperature & 0 to $1200^{\circ} \mathrm{C}$ & $\begin{array}{l}\text { The minimum temperature for TCs should be the ambient ATR } \\
\text { coolant temperature, which is on the order of } 30^{\circ} \mathrm{C} \text {. However, } \\
\text { TCs designed for high temperatures may have some bias at low } \\
\text { temperatures, so the lower limit is set lower than } 30^{\circ} \mathrm{C} .\end{array}$ \\
\hline Gas flow & -2 to $102 \mathrm{sccm}$ & $\begin{array}{l}\text { Gas flows for temperature control normally fall between } \\
\text { a and } 50 \text { sccm. During ATR shutdown, the helium gas flow is } \\
\text { increased to } 100 \text { sccm. }\end{array}$ \\
\hline Gas pressure & 10 to $25 \mathrm{psia}$ & Gas pressure is specified to be $\leq 14.7$ psia. \\
\hline Moisture & 0 to $22,000 \mathrm{ppmv}$ & Valid operating range of the moisture monitoring sensor. \\
\hline Ram gas pressure & -10 to $300 \mathrm{psig}$ & $\begin{array}{l}\text { Excursions well above the highest expected ram gas pressure of } \\
250 \text { psig. }\end{array}$ \\
\hline Load cell & -15 to $700 \mathrm{lbf}$ & Excursions well above the highest expected load of $600 \mathrm{lbf}$. \\
\hline Stack position & 1.0 to $-3.0 \mathrm{in}$. & Excursions in stack position outside the expected range. \\
\hline
\end{tabular}

\subsubsection{Temperature}

No temperature measurements fell outside the range of expected values (Figure 4). Ten temperature values reported as NULL were deleted from the NDMAS database. The desired temperature range in the AGC-3 experiment capsule was $900 \pm 50^{\circ} \mathrm{C}$. The temperature profile through the ATR core was very slight as the result of being able to control temperature in five zones distributed along the length of the capsule. In addition, tungsten gamma heat rods were installed at the top and bottom of the test train to increase temperatures at the top and bottom of the capsule.

\subsubsection{Moisture}

The moisture sensor did not function properly at the beginning of Cycle 152B. A new filter was installed in the moisture sensor prior to reinstalling the AGC-3 experiment capsule in ATR for Cycle 154B. Moisture monitoring began after the capsule was reinstalled for Cycle 154B. Moisture concentrations consistently exceeded 10 ppmv as shown in Figure 5.

\subsubsection{Temperature-Control-Gas Chemical Constituents}

Gas samples collected for analysis of carbon dioxide and carbon monoxide have not yet been analyzed. Results of gas sampling will be Qualified in a separate report. 


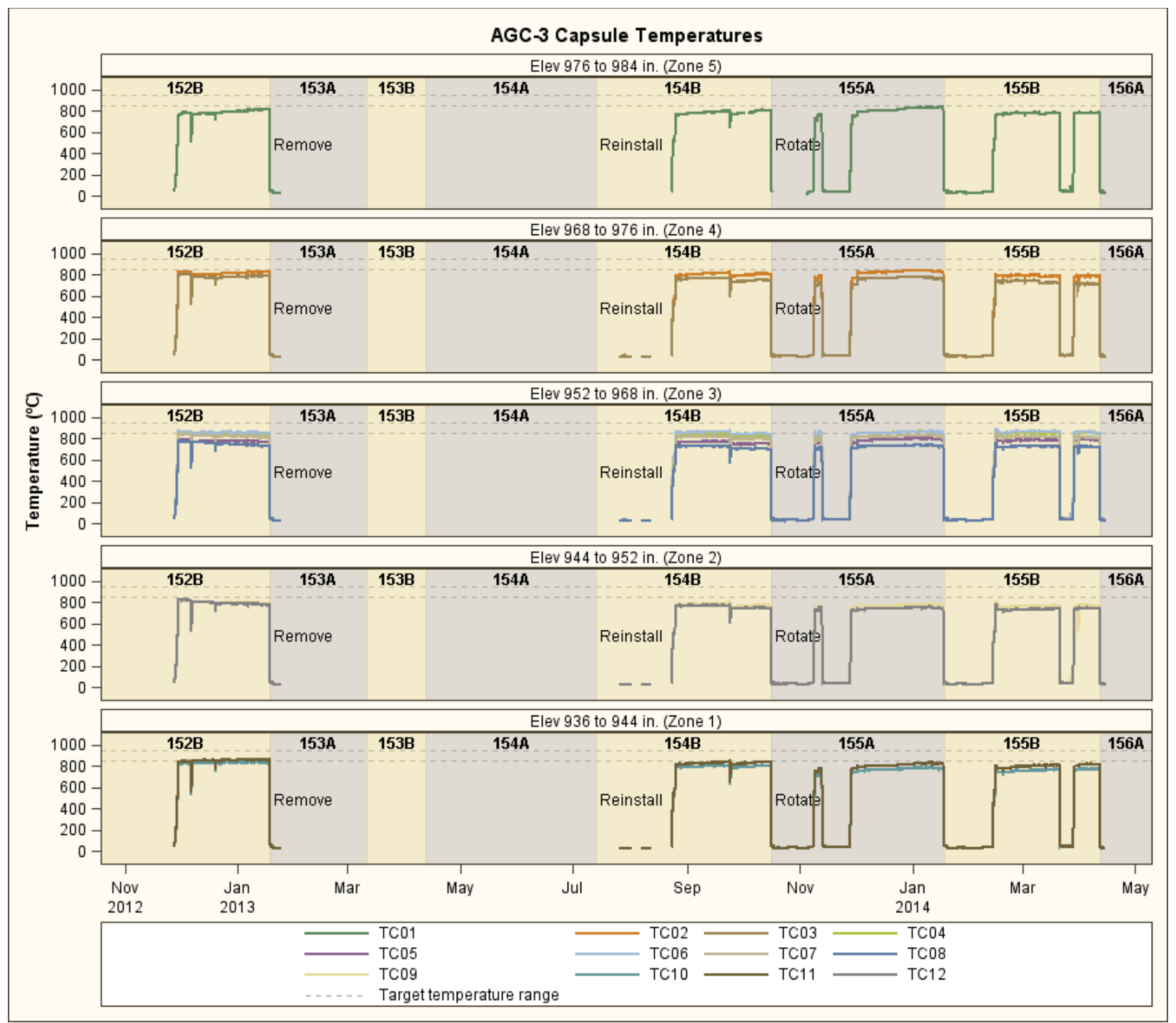

Figure 4. Temperature measured by thermocouples distributed in five vertical zones in AGC-3 experiment capsule.

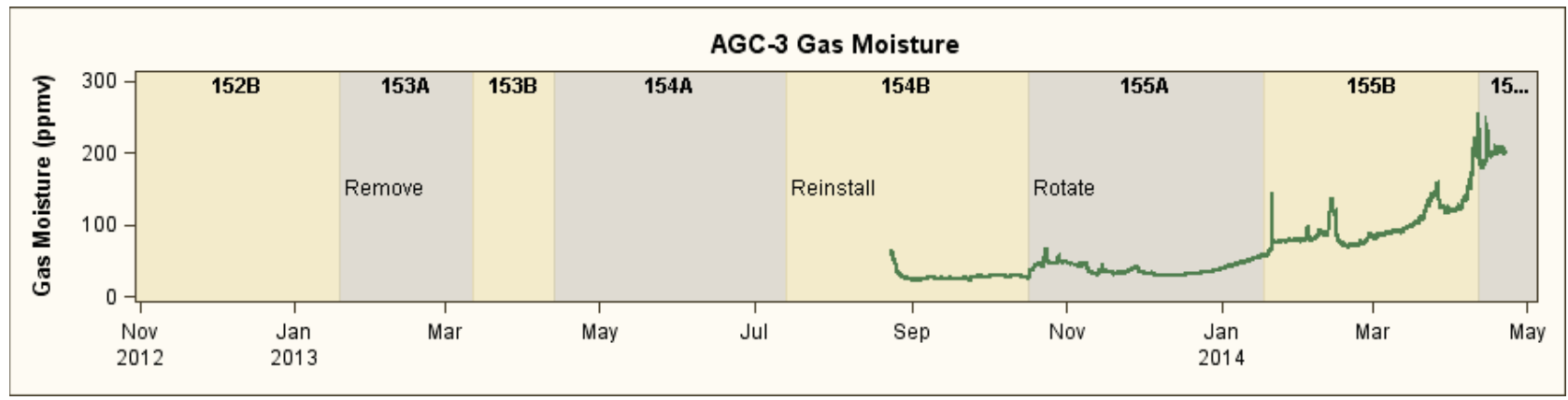

\section{Figure 5. Water vapor concentration in effluent gas line.}

\subsubsection{Load Cell and Displacement Data}

The experiment was planned to load the six outer stacks to three different load levels, with diametrically opposed stacks loaded the same amount. Stack 1 and 4 were to be subjected to the lowest 
load of $13.8 \mathrm{MPa}$. At the beginning of the experiment, when it was uncertain whether Stacks 1 and 4 would be able to be loaded at all, Stacks 2 and 5 were reduced to $13.8 \mathrm{MPa}$ so that two stacks would be subjected to the lowest loadings. Since it is important to have a constant loading throughout the experiment, the loads on Stacks 2 and 5 could not be increased once the leak issues were resolved. As a result, Channels 1, 2, 4, and 5 were loaded to $13.8 \mathrm{MPa}$ (393 lbf, $2000 \mathrm{psi}$ ) while Channels 3 and 6 were loaded to $20.7 \mathrm{MPa}$ (589 lbf, $3000 \mathrm{psi}$ ). Measurement errors were specified at $\pm 5 \%$. The measured loads are plotted in Figure 6. Load data were generally within 5\% of the specified load. Loads to the paired stacks were very similar. The load values fell within the tolerance limits of the experiment plan.

Stack displacement increased consistently throughout the experiment with total displacement ranging from 1 to 1.25 in. (Figure 6). No anomalous values were identified.

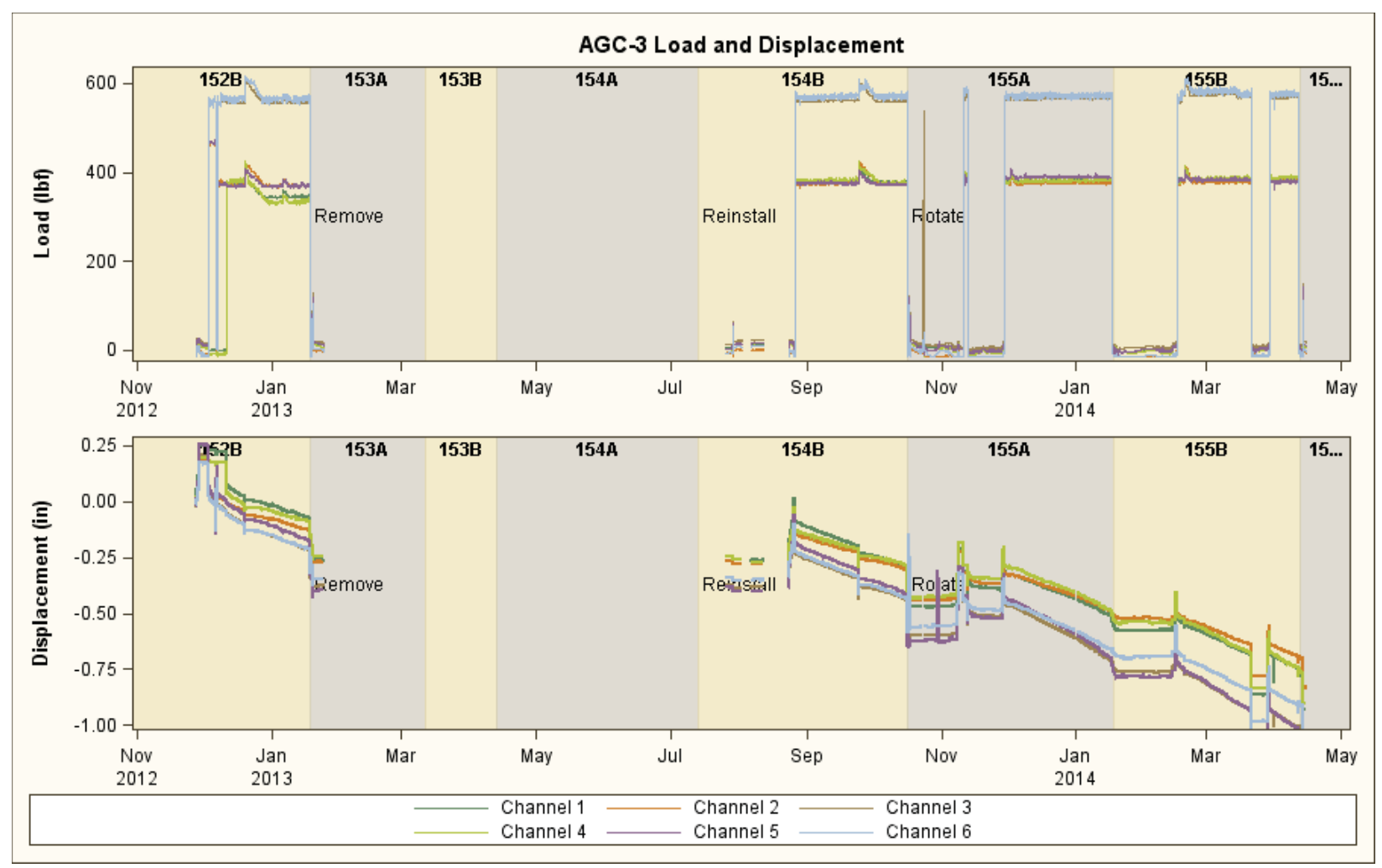

Figure 6. Load and displacement data.

\subsubsection{Gas Flow}

Argon and helium gas was passed through the AGC-3 experiment capsule to control the temperature by altering the thermal conductivity. Seven gas feeds were supplied to provide temperature control along the length of the capsule (Figure 7). During ATR shutdowns, helium flow was increased to $100 \mathrm{sccm}$. Helium and argon gas flow values fell below $0 \mathrm{sccm}$ at times throughout the experiment. The negative gas flows were all just slightly below zero, ranging between -1.177 and $-0.005 \mathrm{sccm}$. These negative gas flow values are within the uncertainty range of the instrument and are not considered failed. All gas flow data were consistent with planned gas flow conditions and expected values. 


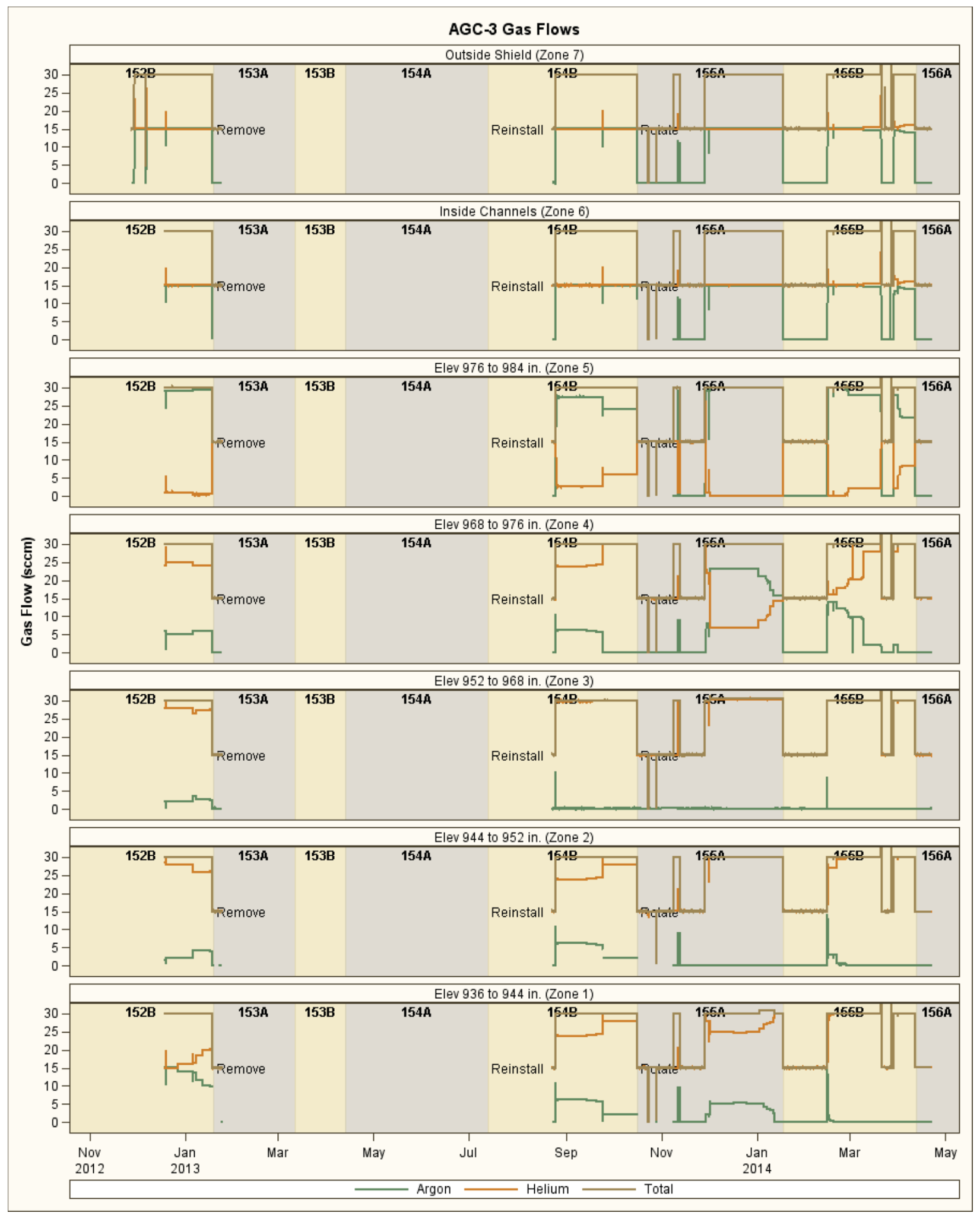

Figure 7. Plots showing argon, helium, and total gas flows through seven zones. 


\subsubsection{Gas Pressure}

Gas pressure values were within expected ranges as shown in Figure 8.

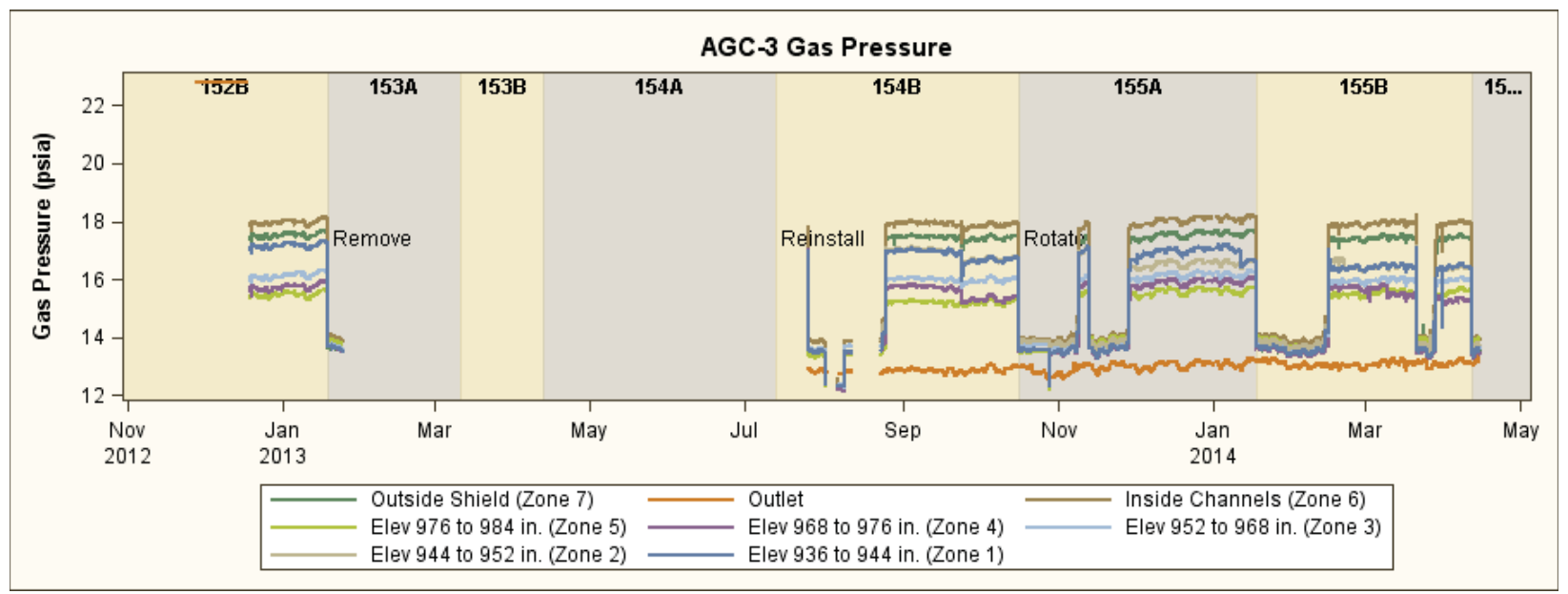

Figure 8. Gas pressure.

\subsubsection{Instrument Failure}

When an instrument fails during the irradiation experiment and this failure is verified during the data qualification process, all future data collected from the instrument are Failed. No instruments failed during the AGC-3 experiment.

\subsubsection{Stack Raise Pressure}

During ATR outages, the stacks of stressed graphite specimens were raised from below to ensure that the specimens were not wedged into the channels. An upper ram pressure of 50 psi was applied to all stacks, then pressure was applied to each individual stack from below while the compression ram pressure was reduced to zero. Each stack was raised individually, thus ensuring that the stack was free to move. This activity was conducted three times during the AGC-3 experiment. The pressure on the lower rams was not differentiated by channel so only total raise pressure was recorded. As shown in Figure 9 through Figure 11, as the ram gas pressure was removed from each channel, the corresponding stack was raised by about 0.1 to 0.4 in. Each stack raised when pressure was applied, indicating that the stacks were not stuck in the channel.

Stacks were raised after Cycle 152B (Cycle 153A outage) as shown in Figure 9, after Cycle 154B (Cycle 155A outage) as shown in Figure 10, and after Cycle 155B (Cycle 156A outage) as shown in Figure 11. This demonstrated that the specimens were free during the previous cycle. Stacks were raised at the end of the AGC-3 experiment to demonstrate that the specimens remained free during the final cycle. All stack raising episodes showed that the stacks were free within the channels. All load data were therefore considered representative of the compressive load applied to the specimens. 


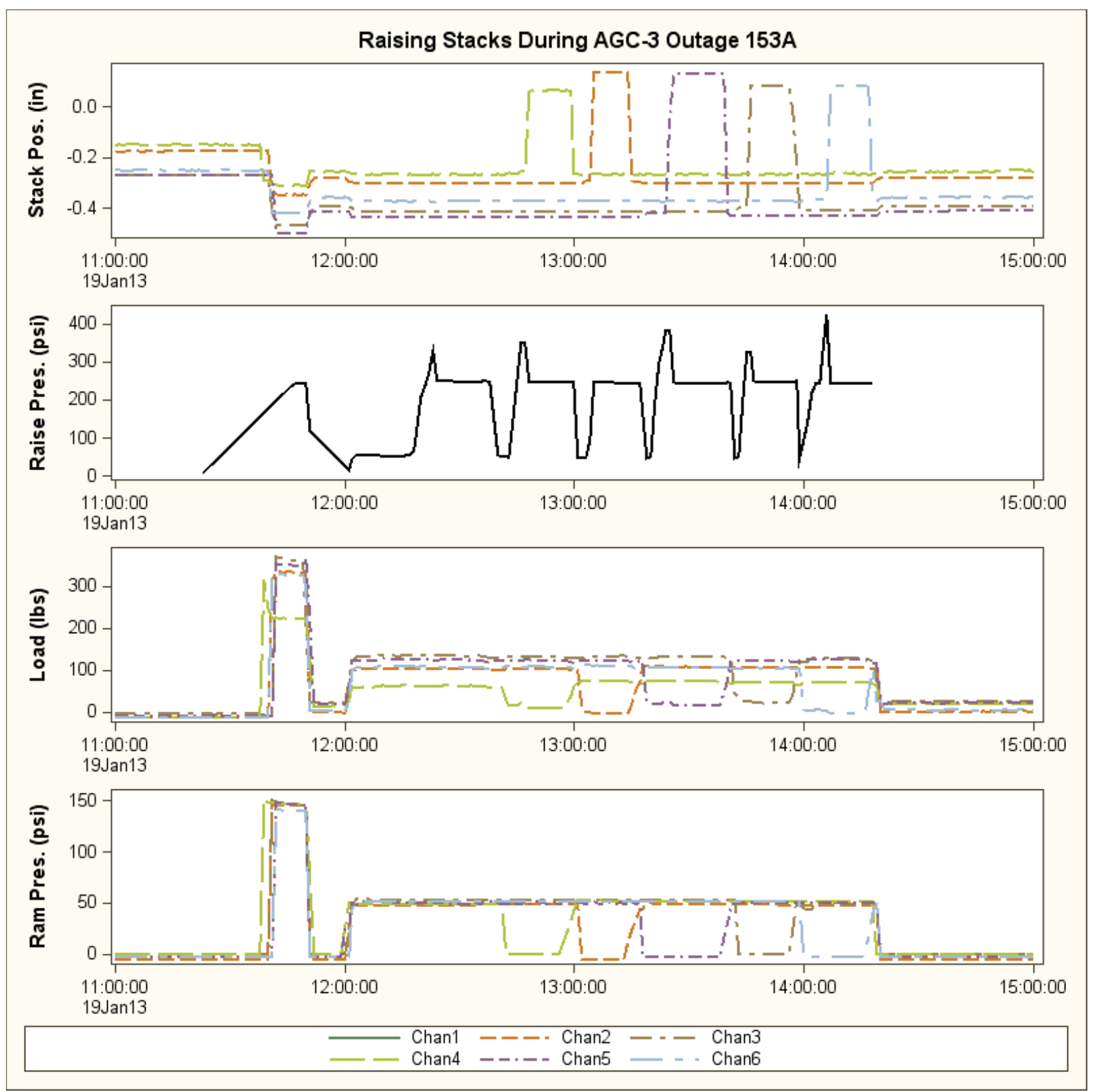

Figure 9. Change in stack position, raise pressure, stack load, and ram gas pressure for stack raising at end of Cycle 152B. 


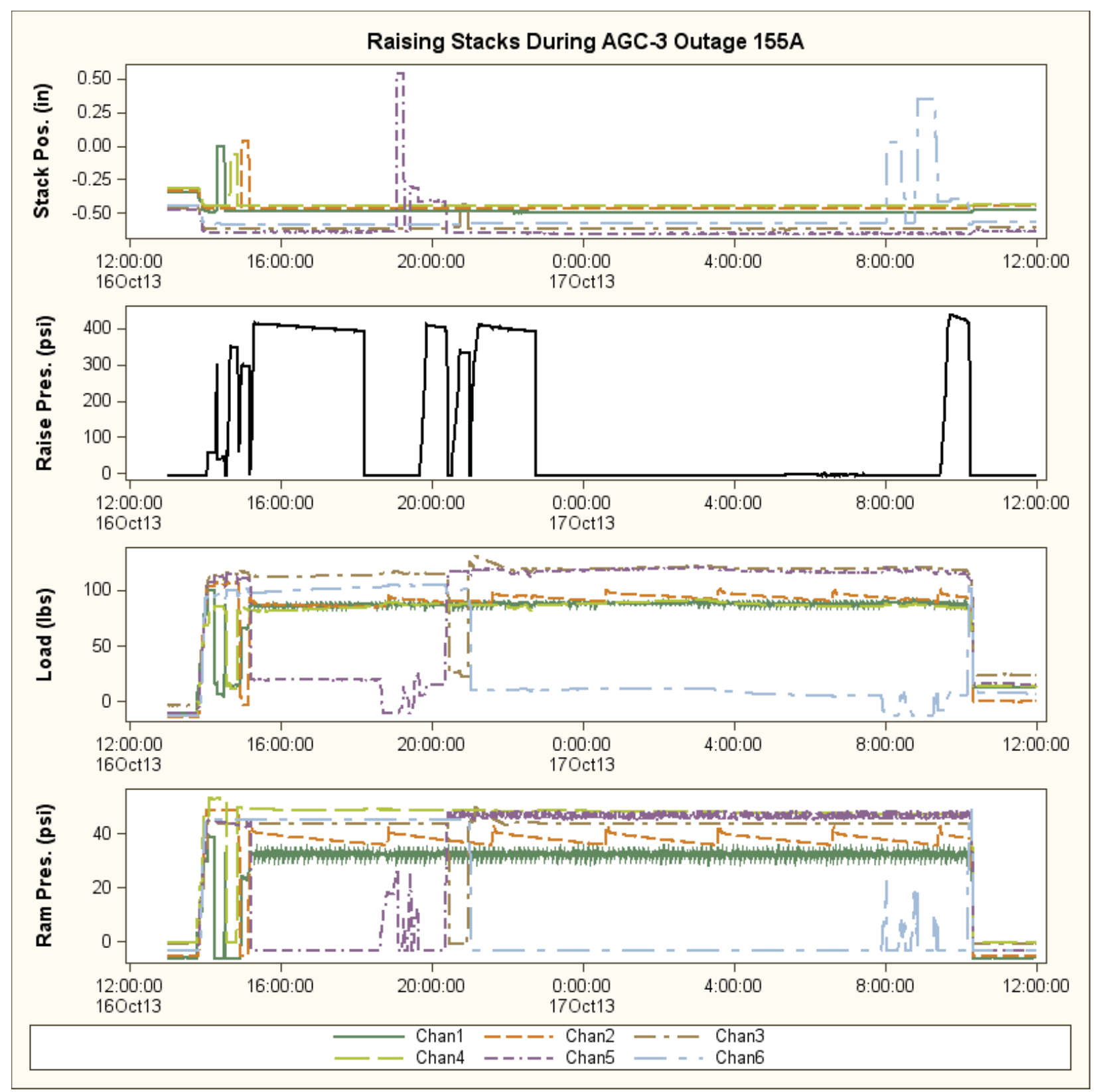

Figure 10. Change in stack position, raise pressure, stack load, and ram gas pressure for stack raising between Cycles 154B and 155A. 


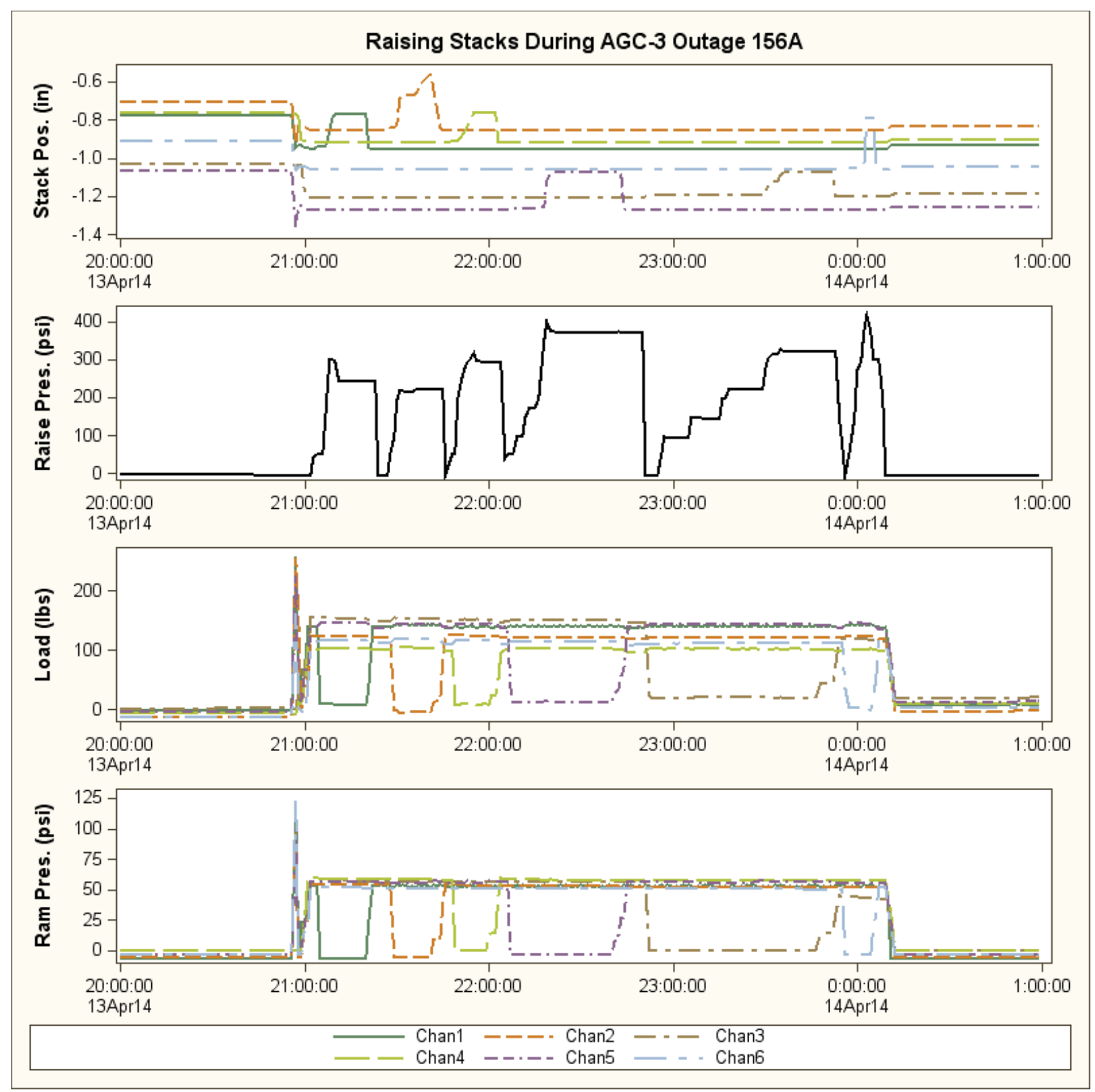

Figure 11. Change in stack position, raise pressure, stack load, and ram gas pressure for stack raising at end of AGC-3 experiment after Cycle 155B. 


\subsubsection{Thermocouple Correlation Analysis}

During the first Advanced Gas Reactor experiment (AGR-1), a number of the TCs formed virtual junctions outside the capsule in which they were installed, causing them to give erroneous readings (INL/EXT-10-18097 ${ }^{16}$ ). One way this was detected was when the TC switched from being highly correlated to adjacent TCs in the capsule, to being highly correlated to TCs farther away. The basis of this comparison is that temperatures measured at a TC will be more highly correlated to TCs installed at the same elevation, or at immediately adjacent elevations, than to TCs installed at more remote elevations. This comparison was applied to the TCs installed in the AGC-3 experiment capsule.

A correlation was calculated daily for each TC with all other TCs. The highest correlation coefficient was selected for each day and plotted on the graphs shown in Figure 12 through Figure 23. Each graph shows the vertical position of the base $\mathrm{TC}$ as a solid green line and the daily maximum correlations to other TCs as circles. Using Figure 12 as an example, TC01 was installed at a height of 978 in. in the ATR core at Level 8. TC01 was most highly correlated with the TCs installed at Level 7 in the core. This behavior was fairly consistent throughout the AGC-3 experiment. Therefore, there was no evidence that TC01 had formed a virtual junction at a different position within the capsule.

Reviewing Figure 13 through Figure 23, the TCs where two TCs were installed at the same level in the capsule were most highly correlated to each other (TC02 with TC03 at Level 7, TC04 with TC05 at Level 6, TC07 with TC08 at Level 4, TC09 with TC12 at Level 3, and TC10 with TC11 at Level 2). Where only one TC was installed at a given level, the TC was most closely correlated to a TC immediately adjacent to (either above or below) that TC. There did not appear to be any evidence of formation of virtual junctions in the AGC-3 experiment capsule.

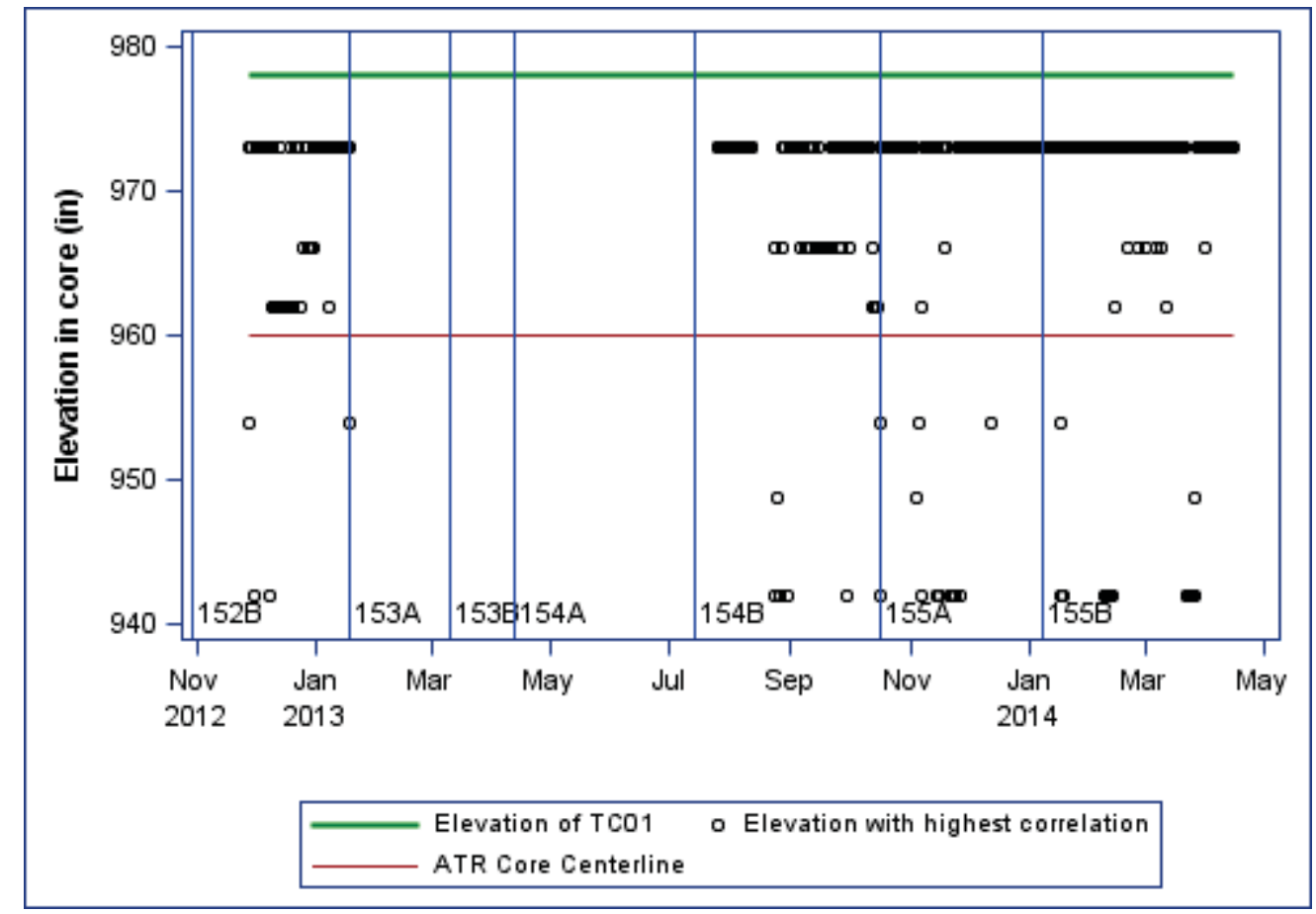

Figure 12. Level of thermocouple with highest correlation to TC01 at Level 8 (978 in.). 


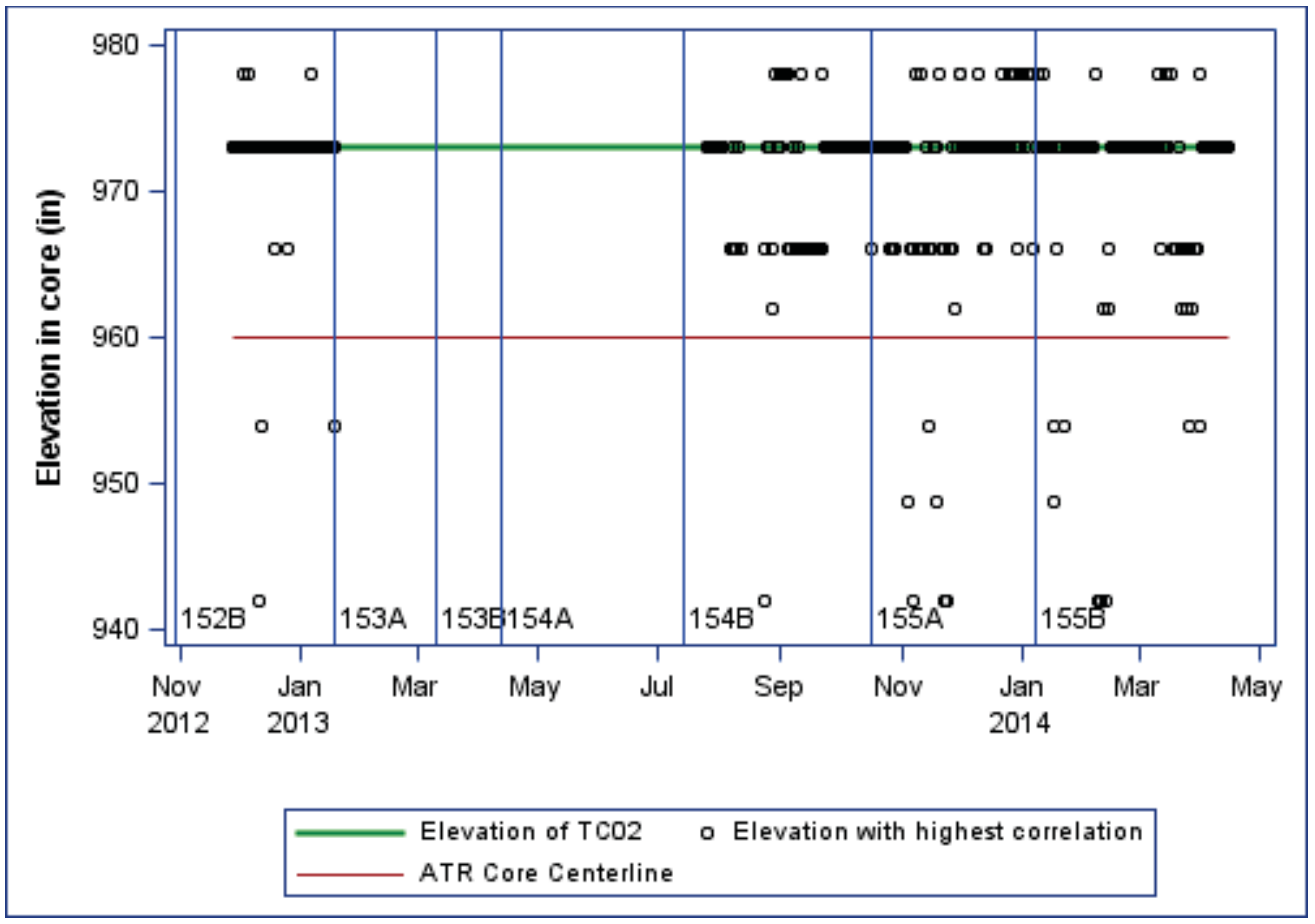

Figure 13. Level of thermocouple with highest correlation to TC02 at Level 7 (973 in.).

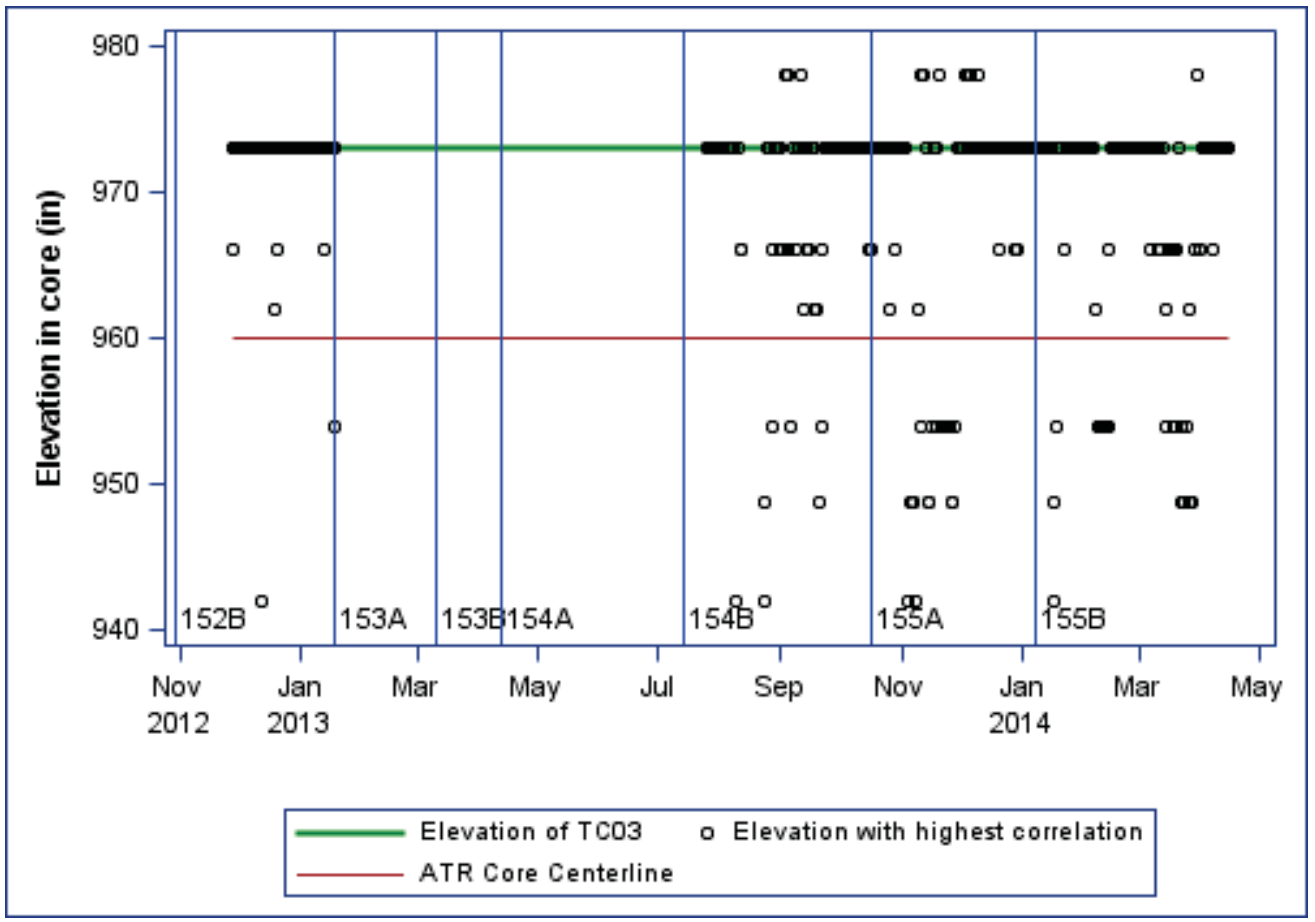

Figure 14. Level of thermocouple with highest correlation to TC03 at Level 7 (973 in.). 


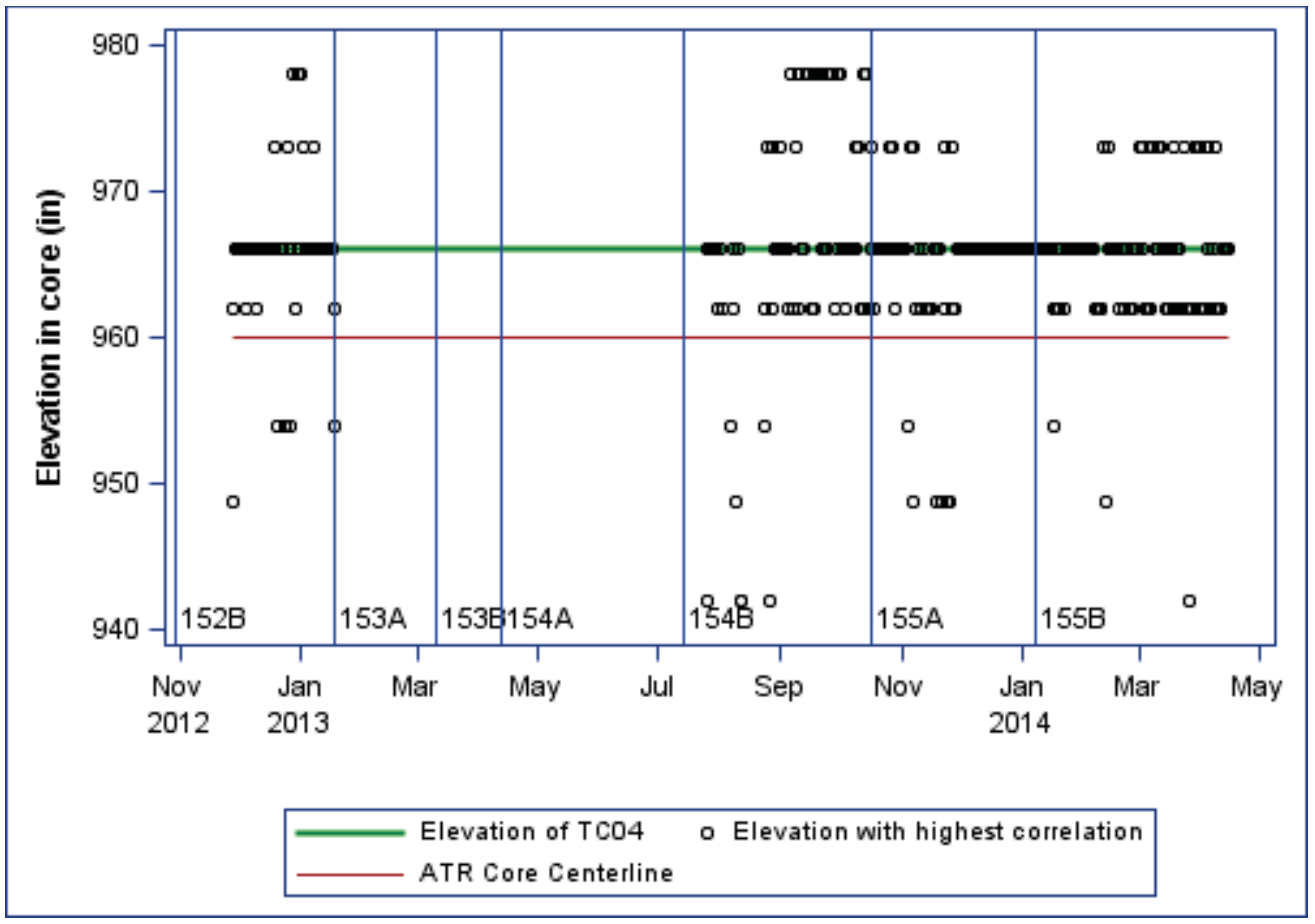

Figure 15. Level of thermocouple with highest correlation to TC04 at Level 6 (966 in.).

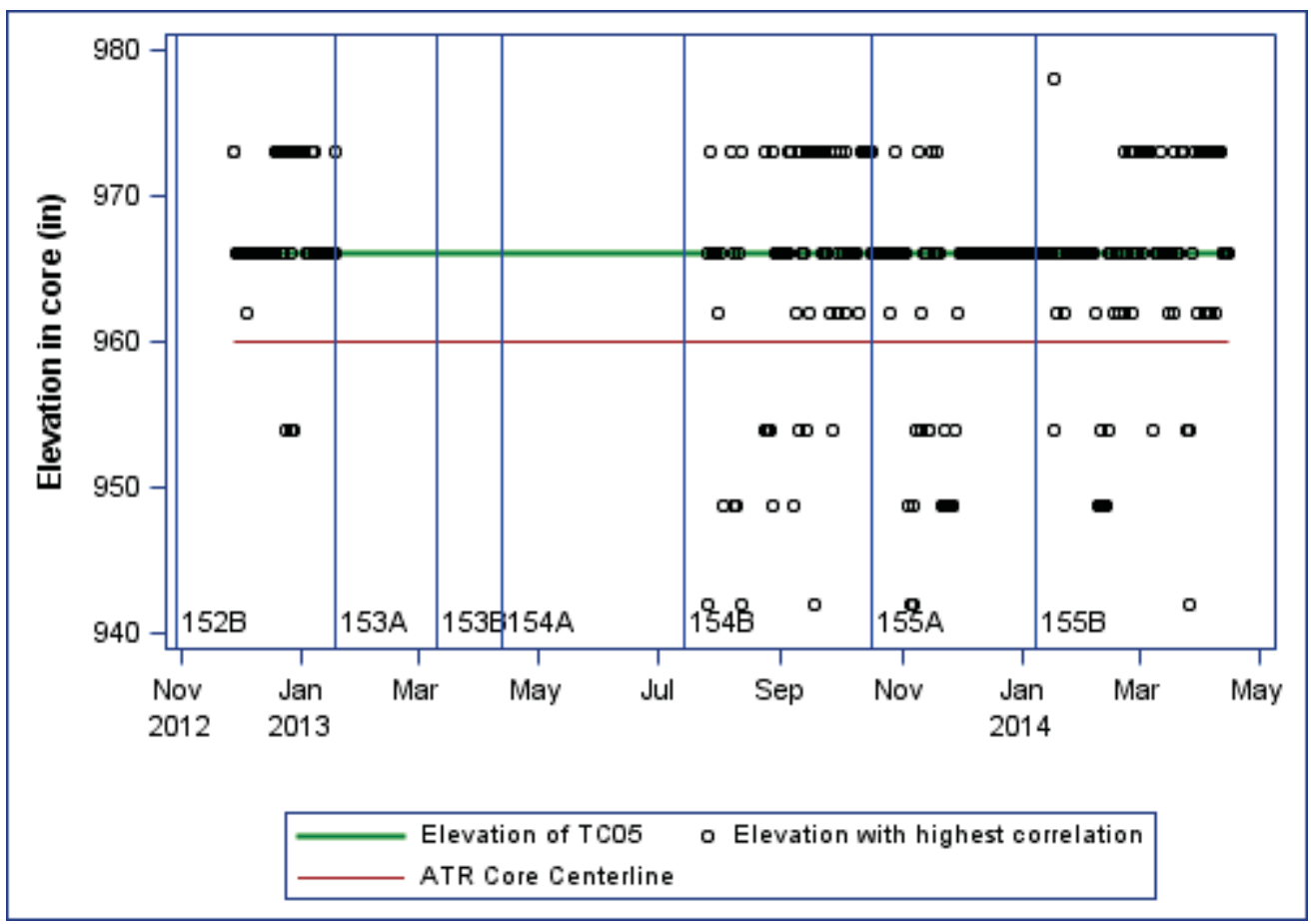

Figure 16. Level of thermocouple with highest correlation to TC05 at Level 6 (966 in.). 


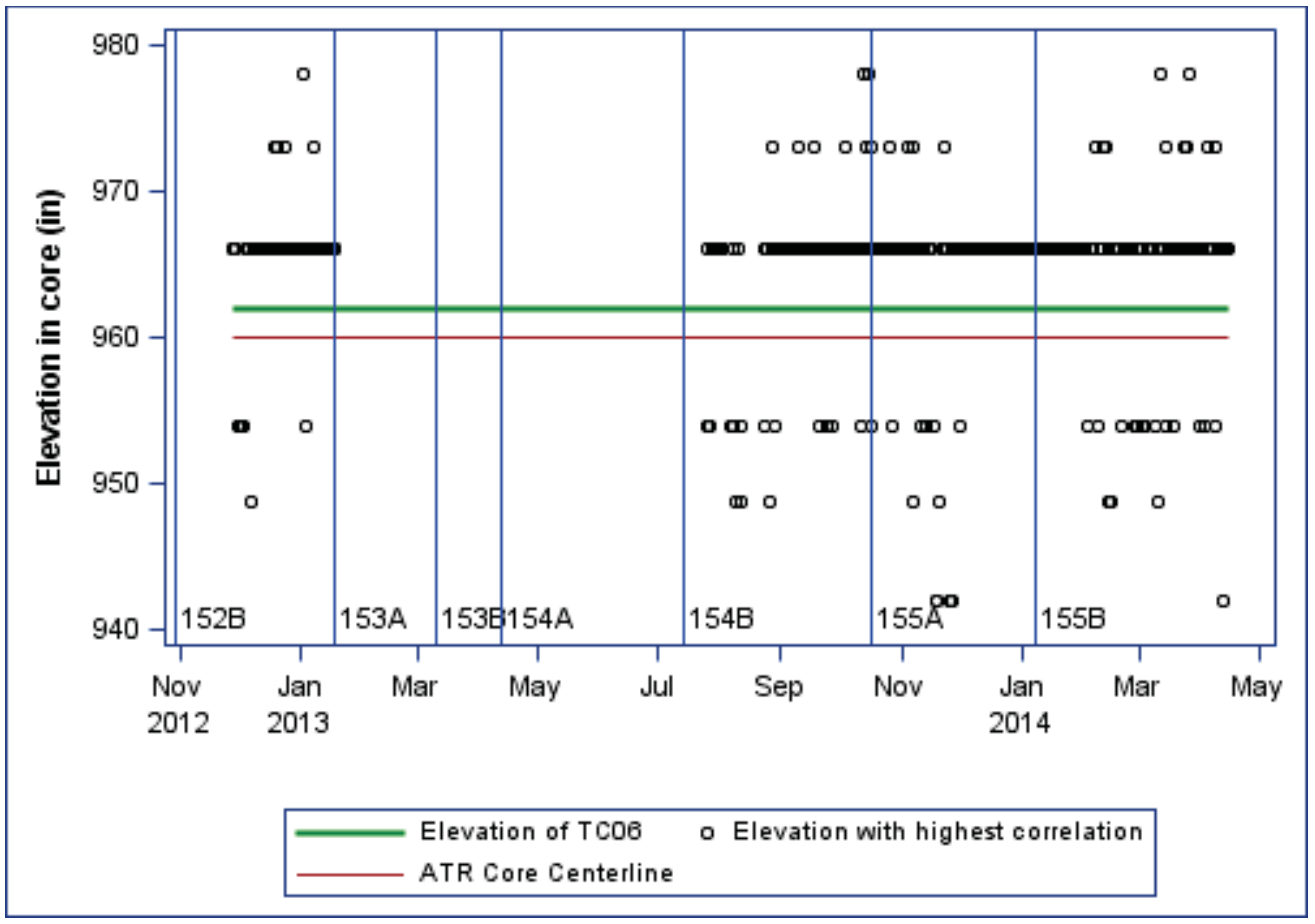

Figure 17. Level of thermocouple with highest correlation to TC06 at Level 5 (962 in.).

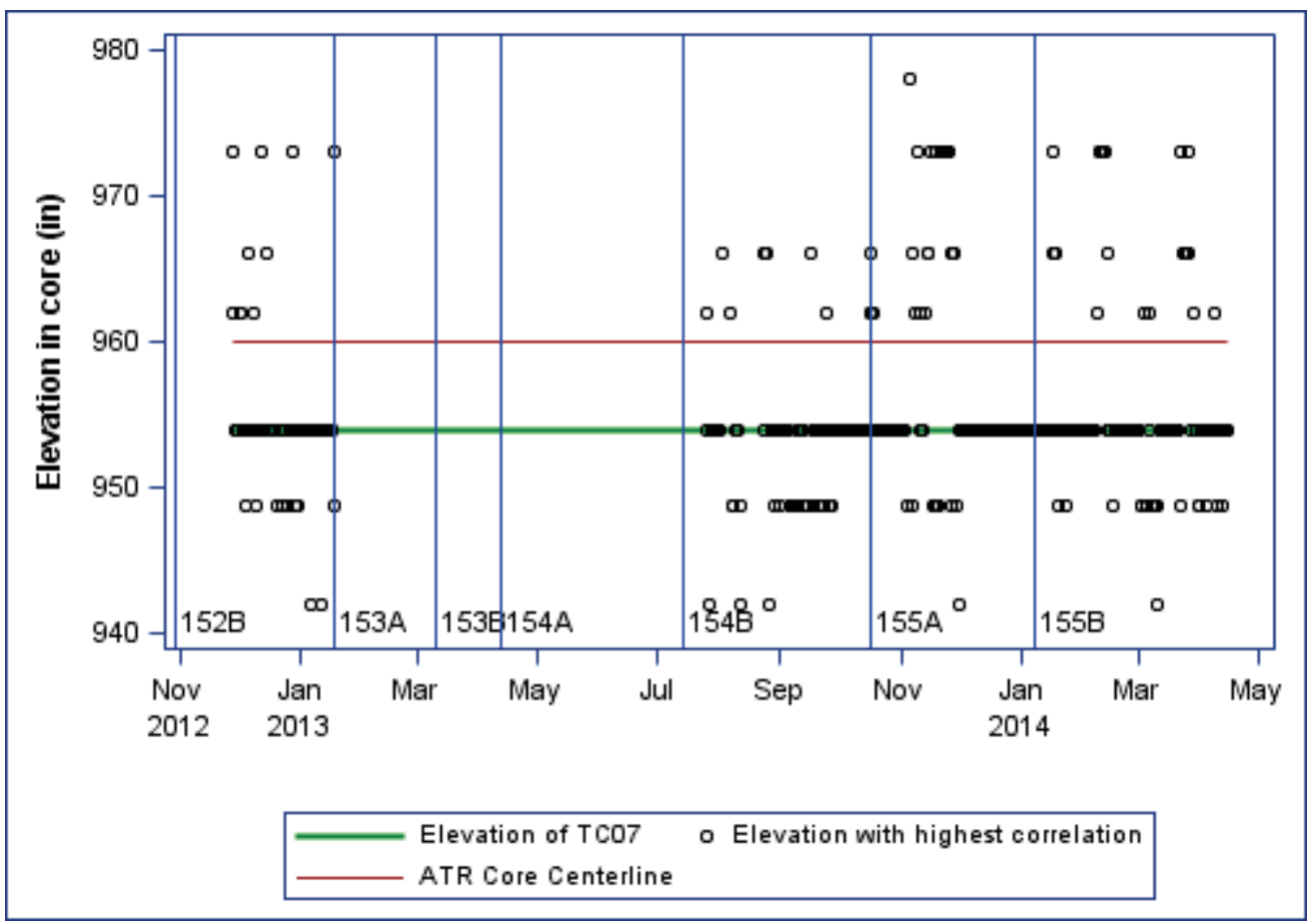

Figure 18. Level of thermocouple with highest correlation to TC07 at Level 4 (954 in.). 


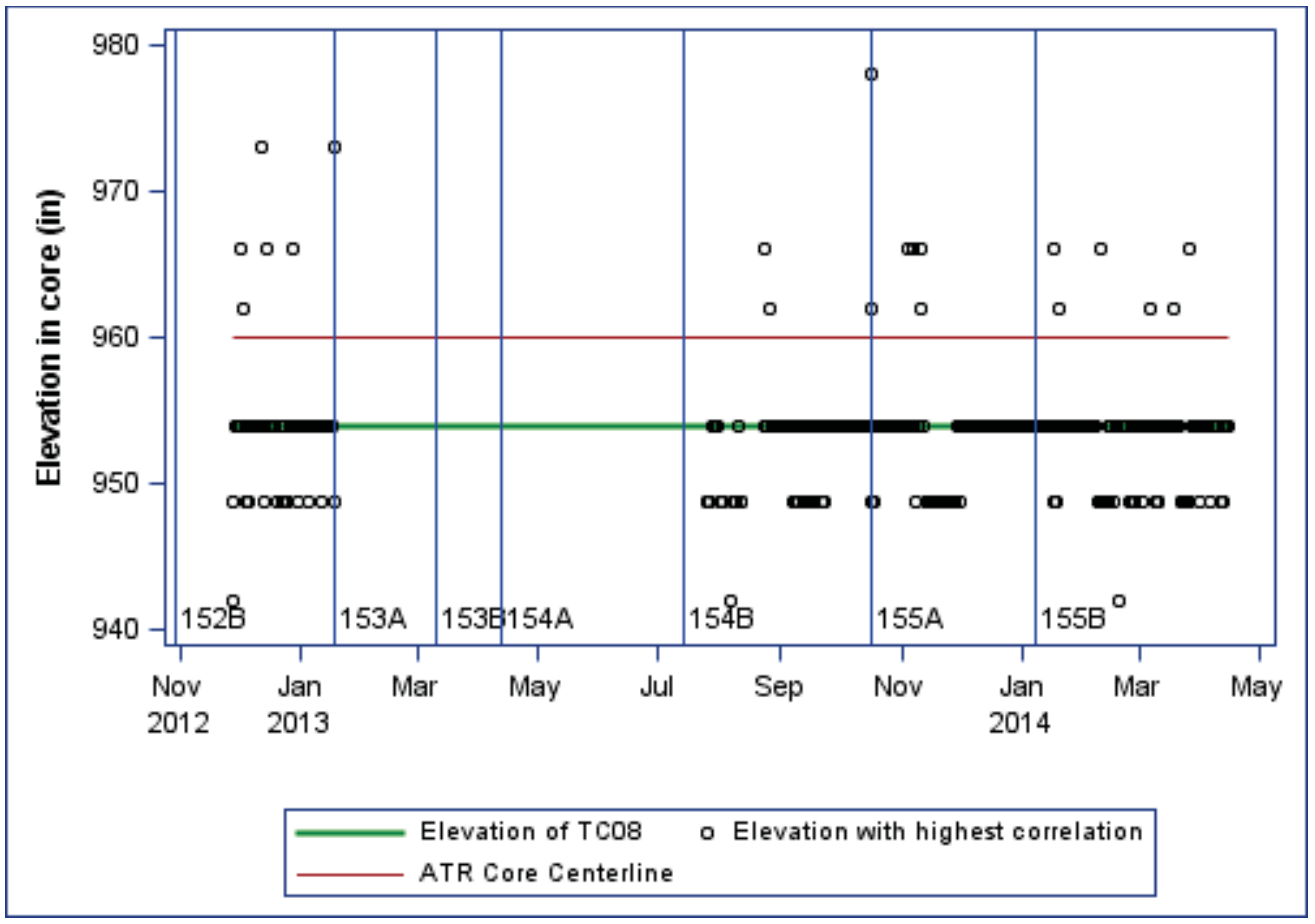

Figure 19. Level of thermocouple with highest correlation to TC08 at Level 4 (954 in.).

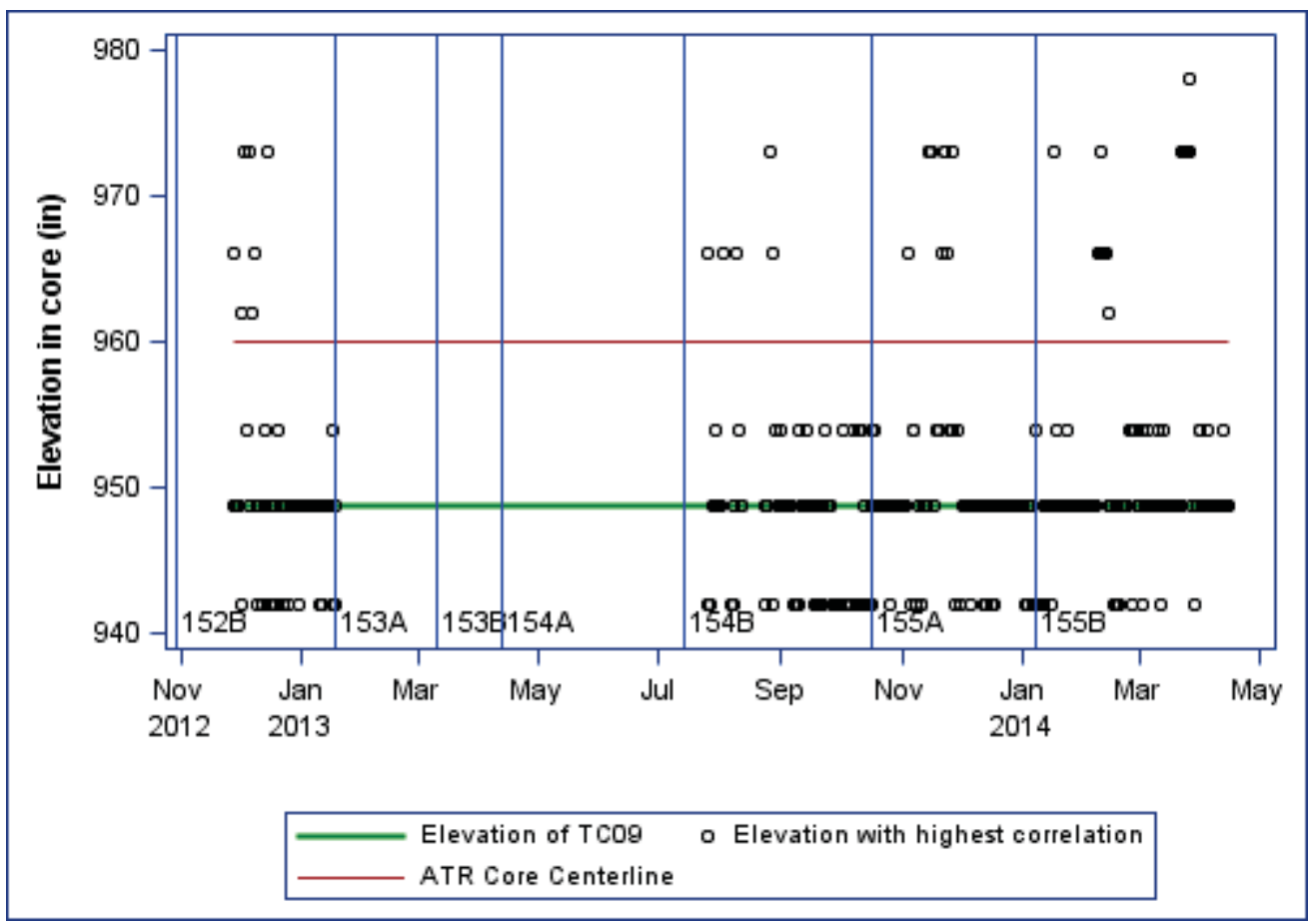

Figure 20. Level of thermocouple with highest correlation to TC09 at Level 3 (948.75 in.). 


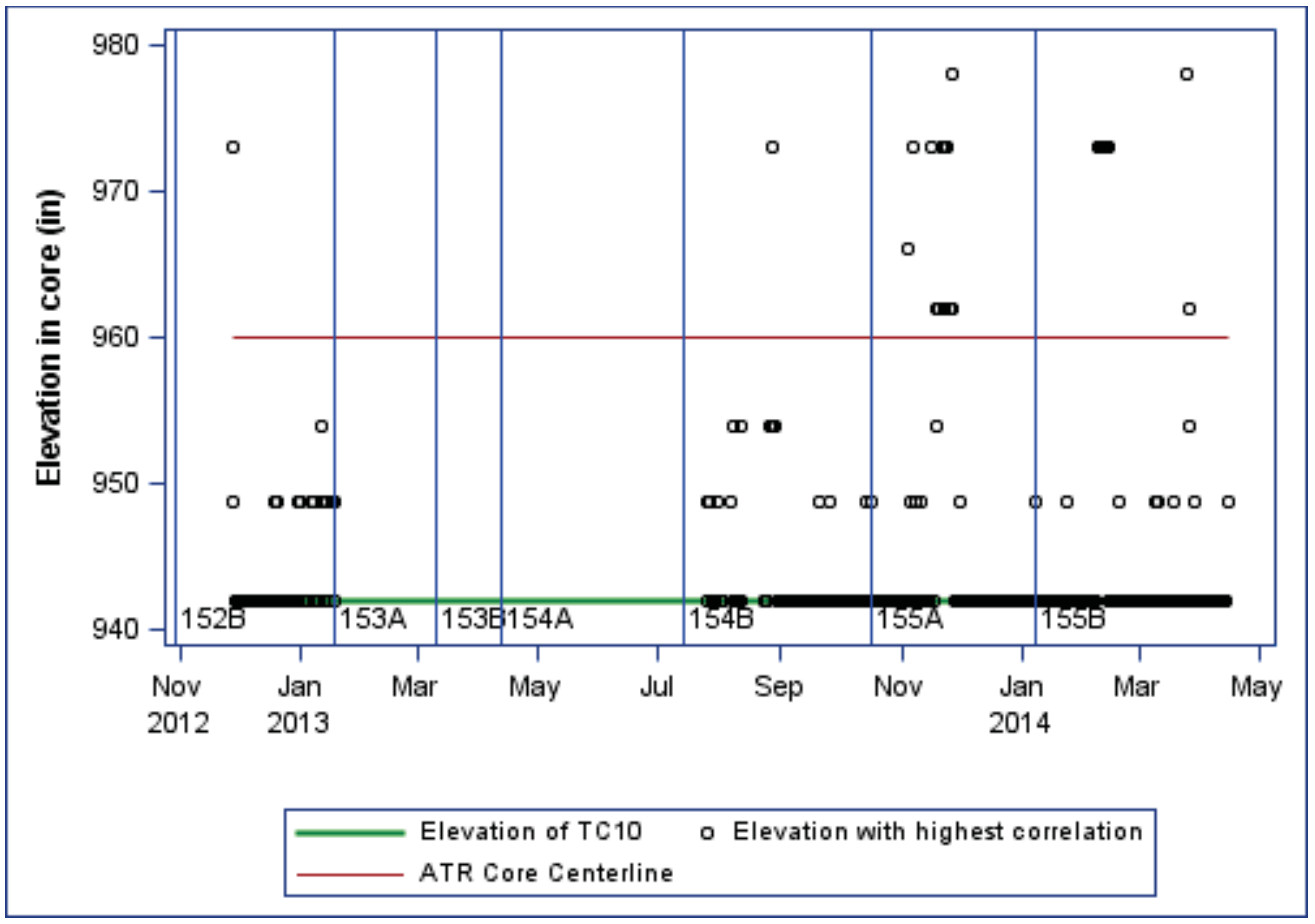

Figure 21. Level of thermocouple with highest correlation to TC10 at Level 2 (942 in.).

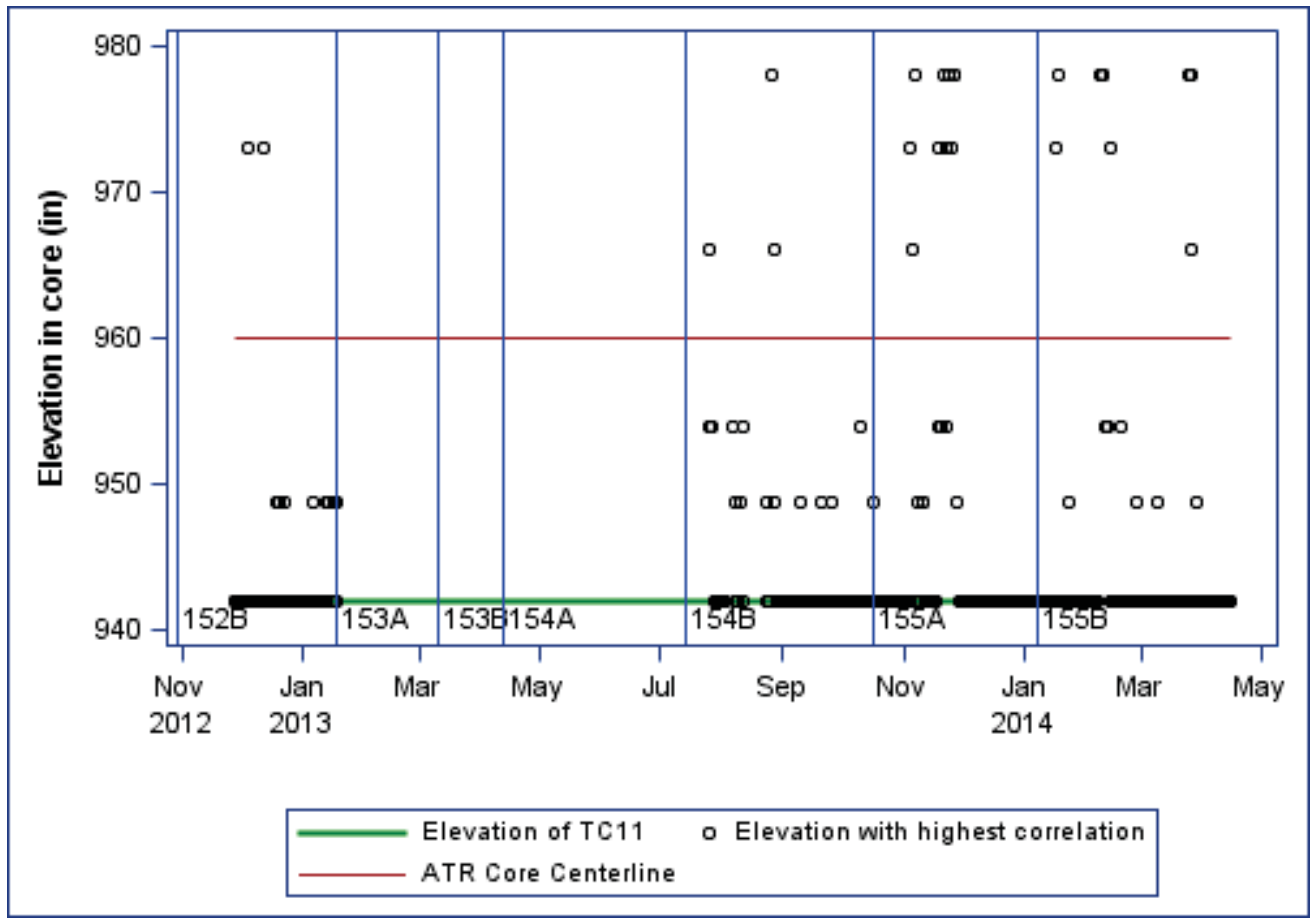

Figure 22. Level of thermocouple with highest correlation to TC11 at Level 2 (942 in.). 


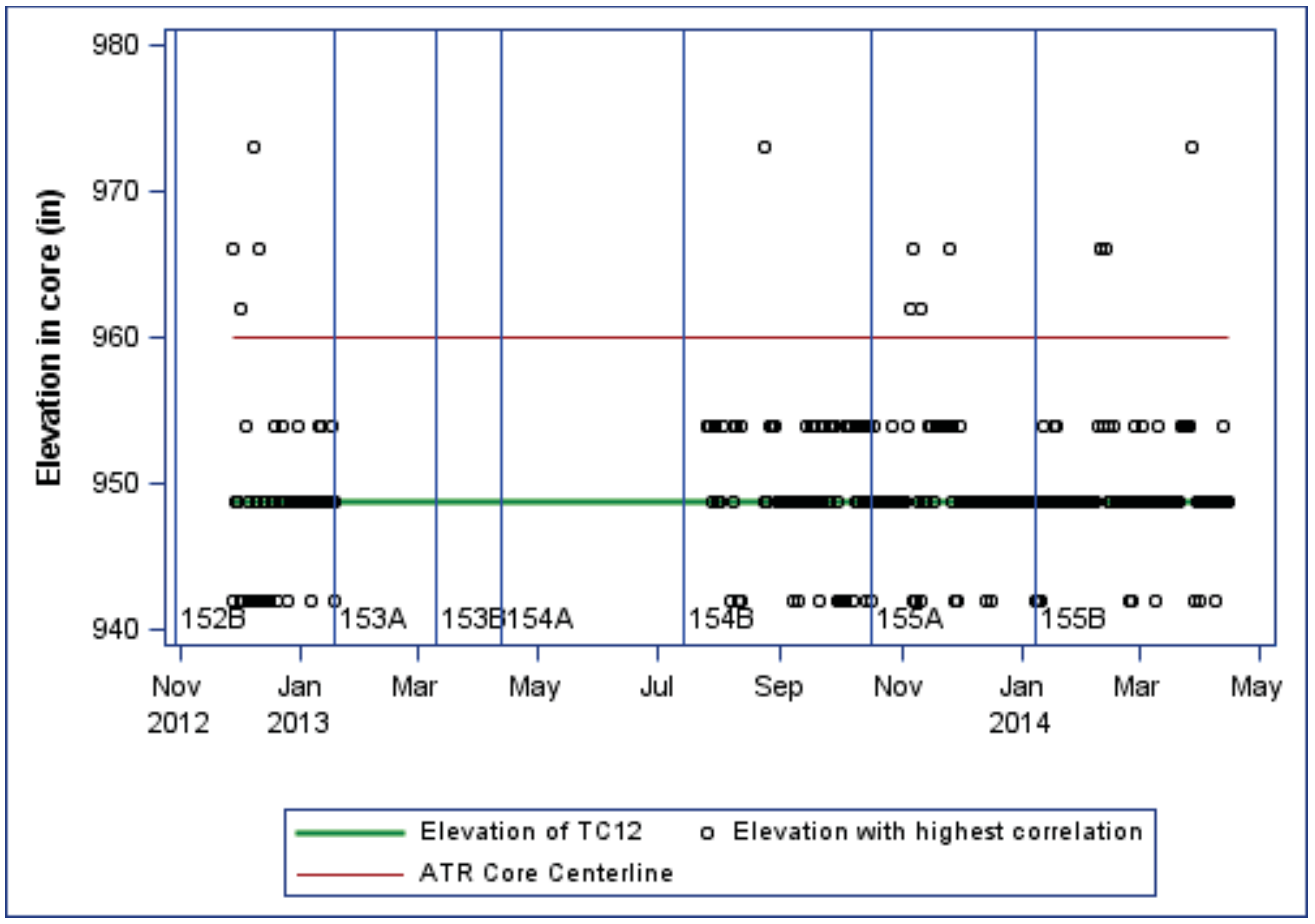

Figure 23. Level of thermocouple with highest correlation to TC12 at Level 3 (948.75 in.).

\subsubsection{Control Charts}

The purpose of control charts is to allow simple detection of events that are indicative of actual process changes. This simple decision can be difficult where the process characteristic is continuously varying. Control charts provide statistically objective criteria for detecting changes. When a change is detected and considered valid, its cause should be identified.

To construct a control chart, a baseline period is selected. Data collected during the baseline period define the expected performance of the data time series. The mean of the response value in the baseline period is calculated using all observations. This mean is used to draw the centerline of the control chart. The standard deviation of the observations is calculated and used to draw the upper and lower control limits at three standard deviations above and below the mean. If the time series has a constant mean and standard deviation, $99.7 \%$ of future points will plot between the upper and lower control limits. In addition to data falling outside the control limits, patterns of data within the control limits can also indicate a change in the process generating the data (Duncan $1965^{17}$; StatSoft Incorporated $2010^{18}$ ).

A control chart is based on the assumption that the mean and standard deviation of the process are constant between the baseline period and the monitoring period. If such an assumption is violated, the control chart cannot be interpreted strictly by the above rules. The AGC-3 experiment covered four ATR cycles over a 17-month period. The capsule was installed in ATR for one cycle (Cycle 152B); removed from ATR during Cycles 153A, 153B, and 154A; returned to ATR for one cycle (Cycle 154B); rotated 180 degrees after Cycle 154B; and irradiated for two cycles (Cycles 155A and 155B). Rotation of the capsule changed the distance between the ATR core center and the TCs. As a result, it did not seem defensible to assume that TC temperatures would maintain a constant mean throughout the AGC-3 experiment. Because of the short duration of the AGC-3 experiment (only four irradiation cycles) and the frequent disturbance of the capsule, control chart analysis was not included in the data quality assessment. 


\section{DATA QUALIFICATION}

Data qualification refers to the multistep process of verifying that the data meet the requirements for the intended use. All AGC-3 experiment irradiation monitoring data were collected within an approved NQA-1-2008/1a-2009, Part I, QA program, and are therefore Type A data. This section discusses the results of data qualification for AGC-3 experiment irradiation monitoring data. The result of the data qualification process is the assignment of a data element to one of the following three categories:

- Qualified. Independent verification documents that the data meet the requirements for a specific end use as defined in a data collection plan and that the data were collected within an NQA-1-2008/1a-2009, Part I, or equivalent QA program. Any nonconformance is concluded to not affect the usability of the data.

- Trend. Independent verification identifies minor flaws or gaps in meeting requirements for data use. Even so, the data still provide information that can be used. Data were collected within an NQA-1-2008/1a-2009, Part I, or equivalent QA program.

- Failed. Independent verification identifies major flaws in meeting data collection requirements. Data do not provide information about the system or object. Data are not useable.

\subsection{Conformance to NQA-1-2008/1a-2009, Part I, Quality Assurance Program}

The verification of data with regard to meeting NQA-1-2008/1a-2009, Part I, QA requirements involves tracing the documentation trail of the data. The process to collect data involves writing a data collection plan and the QA and quality control activities associated with that data. Review of the data collection plan assures that the planned work will generate data of appropriate quality for use in the Graphite Technology Development Program. During data collection, auditors and line managers evaluate the work and ensure it is conducted according to the data collection plan. Metadata generated by the initial documentation, audits, and acceptance inspection provide the evidence that data meet the requirements of an NQA-1-2008/1a-2009, Part I, data collection program. Documentation of compliance is accomplished by reference to documents, which include plans, audit reports, nonconformance reports, and engineering design files.

The following documents provide the evidence that the AGC-3 experiment data meet the QA requirements of NQA-1-2008/1a-2009, Part I:

- PLN-2690-Defines an NQA-1-2008/1a-2009, Part I, compliant QA program.

- PLN-2497-Provides an overall program plan for the graphite technology research and development area.

- TFR-791, TFR-509, and TFR-510 - Provide technical and functional requirements for the irradiation phase of the AGC-3 experiment.

- Inspection Report IAS121679 19 - Reports results of a review of the ATR data source streams. The inspection determined that the equipment used to collect data is calibrated as required by the ATR technical specifications and operating requirements, data collection and transfer systems are verified to function through system testing and operational checks, and software systems meet configuration control and testing requirements. 


\subsection{Design and Instrument Specifications}

Project plans and design documents contain requirements for the construction and instrumentation of the AGC-3 experiment capsule. To assure conformance to these requirements, Engineering Work Instructions were prepared as a detailed checklist with signoffs for each step with hold points for QA review and approval. Completion and acceptance of the Engineering Work Instructions by management and QA provided independent verification that the requirements for construction and instrumentation were met. This included verifying calibration of instruments and testing instruments after installation to ensure they were functional. The completed Engineering Work Instructions are filed in the Idaho National Laboratory Electronic Data Management System under the title "Engineering Work Instructions for Assembling the AGC-3 Experiment." All requirements for construction and instrumentation for the AGC-3 experiment capsule were met and documented in the Engineering Work Instructions.

\subsection{Data Qualification Determination}

This section summarizes the data qualification decisions. Detailed information on the data and technical basis for the decisions are discussed in Section 3. A total of 29,683,751 response values were recorded from irradiation monitoring of the AGC-3 experiment. Of these, 30,208 responses were considered to not represent the system or object being measured. All other data are Qualified for use by the VHTR TDO Program.

\subsubsection{Failed Data}

Gas moisture and ram gas pressure response variables produced Failed data as shown in Table 5. Negative ram gas pressures cannot represent the force being applied to the specimen compression rams. Gas moisture was briefly measured at the beginning of Cycle 152B, but all the values were the same at 335.6174 ppmv. The gas moisture instrument was stuck and not recording the actual gas moisture in the outlet line. The gas moisture instrument was shut off, so no data were delivered to NDMAS after December 18, 2012. When the AGC-3 experiment capsule was reinstalled in ATR for Cycle 154B, the gas moisture instrument was repaired, and moisture data were then included in the data feed to NDMAS.

Table 5. Number and data state assignment of records with reasons for failure for AGC-3 experiment.

\begin{tabular}{|l|c|c|l|}
\hline $\begin{array}{c}\text { Response } \\
\text { Parameter }\end{array}$ & $\begin{array}{c}\text { Total Number } \\
\text { of Values }\end{array}$ & $\begin{array}{c}\text { Number of } \\
\text { Failed Values }\end{array}$ & \multicolumn{1}{|c|}{ Reason for Failure } \\
\hline Gas flow & $8,796,780$ & 0 & \\
\hline Gas moisture & 384,144 & 30,179 & $\begin{array}{l}\text { Between November 27, 2012, and December 18, 2012, } \\
\text { gas moisture was stuck at a constant 335.6174 ppmv. }\end{array}$ \\
\hline Gas pressure & $3,357,715$ & 0 & \\
\hline Temperature & $8,517,015$ & 0 & \\
\hline Load & $2,789,783$ & 0 & \\
\hline Position & $2,788,728$ & 0 & \\
\hline Ram pressure & $3,049,586$ & 29 & $\begin{array}{l}\text { On August 2, 2013, between 5:31 and 16:03, multiple } \\
\text { channels reported a constant negative ram gas pressure } \\
\text { of -75.01717 psig. }\end{array}$ \\
\hline Total & $29,683,751$ & 30,208 & \\
\hline
\end{tabular}

\subsubsection{Trend Data}

No data were identified as Trend in this data set. 


\subsubsection{Qualified Data}

Specimen stacks were compressed at two loads instead of three loads. This may affect the distribution of specimens across the load for future analysis. However, the loads were applied at a constant value during essentially the entire AGC-3 experiment, so that the loads that were applied were an accurate representation of the stack loads. Stacks were raised two times during the experiment and at the end of the experiment. The stacks showed movement each time indicating that they were free to move in the channels. Therefore, the stack loading data are Qualified for use by the VHTR TDO Program.

All other data collected from the AGC-3 experiment for the response variables discussed in this report were judged to meet the requirements specified in the in data collection plans. The response variables Qualified for use by the VHTR TDO Program are TC temperatures, pneumatic ram pressures, load cell output, stack position, constituent temperature-control-gas flow rates, gas moisture, and gas pressure.

\subsection{Corrective Actions}

No corrective actions were identified.

\section{DATA ACCESS}

Graphite irradiation monitoring data have been uploaded to the NDMAS webpage for easy access by VHTR TDO Program participants. A tab has been created on the webpage dedicated to the graphite irradiation experiment data. The graphical summary plot on the webpage provides experiment-long figures for temperature, gas flows, and creep specimen loading. There are four links on the webpage. Three links provide access to temperature, gas flow, and load data that can be downloaded for analysis. The fourth link provides access to graphs of stack raising.

\section{QUALITY ASSURANCE}

NDMAS activities were conducted within the requirements of PLN-2690. Software QA requirements for NDMAS are contained in MCP-3058. ${ }^{20}$ Because graphite will be used as a structural component in the core of a nuclear reactor, the data collection program was conducted within an NQA-1-2008/1a-2009, Part I, QA program. The Idaho National Laboratory data quality level for graphite data is Quality Level 2.

\section{REFERENCES}

1. PLN-2497, 2010, “Graphite Technology Development Plan,” Rev. 1, October 4, 2010, Idaho National Laboratory, Idaho Falls, ID.

2. MCP-2691, 2012, “Data Qualification,” Rev. 2, July 20, 2012, Idaho National Laboratory, Idaho Falls, ID.

3. PLN-2494, 2014, "Very High Temperature Reactor Technology Development Office Program Management Plan," Rev. 12, March 31, 2014, Idaho National Laboratory, Idaho Falls, ID.

4. ECAR-1788, 2012, "Reactor Physics Projections for the AGC-3 Experiment Irradiated in the ATR East Flux Trap,” Rev. 0, April 19, 2012, Idaho National Laboratory, Idaho Falls, ID.

5. TFR-791, 2012, "NGNP Advanced Graphite Capsule AGC-3 Experiment Test Train,” Rev. 1, June 14, 2012, Idaho National Laboratory, Idaho Falls, ID.

6. TFR-509, 2011, “Advanced Graphite Capsule Temperature Control System,” Rev. 2, December 8, 2011, Idaho National Laboratory, Idaho Falls, ID.

7. TFR-510, 2013, “Advanced Graphite Capsule Compressive Load Control Gas System,” Rev. 3, June 18, 2013, Idaho National Laboratory, Idaho Falls, ID.

8. NQA-1-2008, “Quality Assurance Requirements for Nuclear Facility Applications,” Part I, 
Requirements for Quality Assurance Programs for Nuclear Facilities (From Former NQA-1), American Society of Mechanical Engineers.

9. NQA-1a-2009, "Addenda to ASME NQA-1-2008, Quality Assurance Requirements for Nuclear Facility Applications," Part I, Requirements for Quality Assurance Programs for Nuclear Facilities (From Former NQA-1), American Society of Mechanical Engineers.

10. PLN-2690, 2014, "VHTR Technology Development Office Quality Assurance Program Plan," Rev. 12, February 4, 2014, Idaho National Laboratory, Idaho Falls, ID.

11. Form 435.77, 2007, "Next Generation Nuclear Plant Project Information Input Sheet,” Rev. 3, December 3, 2007, Idaho National Laboratory, Idaho Falls, ID.

12. PLN-3319, 2012, "Records Management Plan for the VHTR Technology Development Office Program,” Rev. 2, May 16, 2012, Idaho National Laboratory, Idaho Falls, ID.

13. PLN-2709, 2011, "Very High Temperature Reactor Program Data Management and Analysis Plan," Rev. 3, July 11, 2011, Idaho National Laboratory, Idaho Falls, ID.

14. Hull, L. C., 2012, NDMAS System and Process Description, INL/EXT-12-27594, Rev. 0, October 31, 2012, Idaho National Laboratory, Idaho Falls, ID.

15. Gentillon, C. D., M. L. Abbott, L. C. Hull, B. Pham and M. A. Plummer, 2011, NGNP Data Management and Analysis System Analysis and Web Delivery Capabilities, INL/EXT-09-16327, Rev. 2, September 14, 2011, Idaho National Laboratory, Idaho Falls, ID.

16. Pope, M. A., 2012, AGR-1 Irradiation Test Final as-Run Report, INL/EXT-10-18097, Rev. 2, June 7, 2012, Idaho National Laboratory, Idaho Falls, ID.

17. Duncan, A. J., 1965, Quality Control and Industrial Statistics, Third Edition., Richard D. Irwin, Inc., Homewood, IL.

18. StatSoft Incorporated, 2010, Electronic Statistics Textbook, StatSoft, Incorporated.

19. Report IAS121679, 2012, Review of INL QA Program Execution for NDMAS ATR Data Source Streams Idaho National Laboratory, Idaho Falls, ID.

20. MCP-3058, 2012, "VHTR TDO Software Quality Assurance," Rev. 2, Idaho National Laboratory, Idaho Falls, ID. 
Appendix A

\section{Credentials of Technical Reviewer}




\section{Appendix A}

\section{Credentials of Technical Reviewer}

Kevin Clayton

Kevin has over 25 years of experience in the various aspects of reactor experiment design, analysis, and operation. Kevin's experience includes several innovative and unique designs of the more complex capsules and support systems installed in the Advanced Test Reactor. Kevin is knowledgeable of the Advanced Test Reactor authorization basis, American Society of Mechanical Engineers code and analysis requirements, Idaho National Laboratory welding and inspection requirements, and both industry and Idaho National Laboratory design processes. Kevin has chaired or participated in several design verification processes based on experience in experiment design and fabrication. 